\title{
La cruz en la joyería tradicional salmantina: Sierra de Francia y Candelario
}

Nos limitamos en este estudio al análisis material y formal de la cruzjoya, sin entrar en el ámbito de lo religioso, los aspectos sociales y simbólicos, o su sentido protector. Sí nos parece necesario definir las vías de importación y exportación de las joyas en esta comarca, a través de ferias y mercados ${ }^{1}$, subrayando la importancia de los arrieros y trajineros serra-

1 Principales hitos que documentamos sobre el comercio en la Sierra de Francia.El mercado semanal y el ordinario en Miranda del Castañar, establecidos probablemente en tiempos de Alfoso IX y refrendados en las Ordenanzas del siglo XVI (B.U.S.). - Carta de los RR.CC. a Sancho de Rojas, corregidor de la villa de Miranda "para que no se cometan abusos de alcabalas contra los mercaderes [mirandeños] que llevan a vender fuera de la dicha villa e su tierra" (AGS. RGS, II, año 1486, f.162).-Los feriantes albercanos eran obligados a pagar un talego de moneda blanca al regidor de Granadilla (a cuya jurisdicción pertenecían) en la feria de octubre de Medina del Campo (AGA, Legajo 4. ${ }^{\circ}$, "Antiguas Provisiones del Duque de Alba", 18-IX del 1456).-....A los albercanos q binieren de mercados e caminos luengos en día de fiestta" (AGA, Executoria de 1670 en que se alude a las Ordenanzas locales de 1515; ff.133-133v). - La venta de productos de Cepeda a otro lugar en domingo (Ordenanzas de Cepeda año 1544, col. part.).-La ciudad de Salamanca exime a los albercanos de pagar alcabala por acudir a esta ciudad al mercado franco de los jueves, establecido en 1529 (AGA, Legajo 4. ${ }^{\circ}$, año de 1577), al que alude Tirso en La Peña de Francia: “irá el jueves al mercado, con los pastores del Conde [¿de Miranda?], con las cosas de la tierran.- -Sobre los productos que venden los mercaderes albercanos en Salamanca (AGA, Legajo 4. ${ }^{\circ}, 3$-IX de 1540).-Sobre los aranceles que se cobraban en Miranda del antiguo portazgo a cuantos transitasen por ella con mercancía (AGA, Legajo 4. "Antiguas Provisiones del Duque de Alba", 25-II de 1530; traslado de otro anterior). - La feria de la Peña de Francia que se celebraba tradicionalmente el 6,7 y 8 de septiembre, se traslada al 2 de julio al hacerse franca por privilegio de Carlos II en 29-II de 1672 (AHN. Clero, Libros, 10585, Privilegios de la Peña de Francia)._ a... a la festividad de aquel célebre santuario acuden de su comarca como a feria de todo género de oficiales; y así, había tiendas de diversas mercancías entre las cuales había dos plateros que tenían en ellas muy curiosas y ricas joyas de oro y bien labradas piezas de plata. [A. CASTIllo SolóRZANo, Aventuras del Bachiller Trapaza (Madrid: Cátedra, 1986, ed. de J. Joset), p. 77].-La villa de Tamames tenía cinco tiendas abiertas todo el año, que sacaba a la plaza los días de mercado, todos los martes con mercado franco (AHPS. Cat. 2383 p. $^{\text {a }}$ 29, f.41v).-Entre 1750 y 1783 en la Relación de criados del Monasterio del Zarzoso se incluyen en la soldada unos reales "para ferias" como la del Cristo de la Luz, que se celebra allí cada 14 de septiembre (AHN. Clero, Libros Gastos 
nos y candelarios, y, sobre todo, establecer una tabla cronológica de los plateros y escuelas, locales o de centros urbanos, que trabajaron aquí o recibieron encargos.

Intentamos exponer, de manera práctica, la metodología de esta joya que puede adscribirse a la familia de los collares (o "de colgar al cuello"), la familia de colgar de los brazos (brazaleras), o como joya de las manos (rosarios y camándulas). Utilizamos como vías las fuentes documentales $^{2}$, la iconografía, el trabajo de campo y la pieza-testigo, analizando todas las posibilidades que esta joya ofrece: años en que aparece y desaparece, número de veces que se registra, materiales de que se compone o fábrica, elementos de que consta y guarnición con que se adorna, voces con que se denomina, variantes que presenta, precios en que se estima y peso y tamaño que alcanza, situación en el cuerpo, calidad y estado en que se encuentra, finalidad con que se utiliza, compra o regala y su reutilización si se da; y, si es posible, su procedencia.

Puede a veces resultar críptica la lectura de la joya por la riqueza y complejidad de términos con que es descrita, voces que en ocasiones son solo propias de los plateros locales. Por ello, es necesaria a veces la utilización de sinónimos y siempre deseada la elaboración de glosarios. Esta dificultad y una obligada parcialidad de resultados seguirá existiendo mientras no se aborde en profundidad el estudio de todas las comarcas naturales, para poder obtener resultados globales y más objetivos.

Aunque es válido, como fin en sí mismo, el estudio cerrado de las joyas, intentamos además con ello el mejor conocimiento de esa sociedad que las utiliza.

de 1749,11164 , f.74 y ss.).-Sobre la decadencia, en 1766, de la feria de San Marcos en Cepeda que se remonta al menos a los primeros años del siglo XVI ver en APC, Becerro de 1766, f.279. - Larruga menciona la feria de Ciudad Rodrigo el "Martes de la Ascensión [a la que] concurren gentes de Béjar" y por tanto de Candelario (Memorias... T. XXXV).-En el mercado de los domingos que se mantuvo hasta los años treinta en la Alberca, el lienzo oeste de la plaza estaba reservado a los plateros.

2 Las fuentes documentales de las que fundamentalmente nos hemos servido en este estudio pertenecen al Archivo Histórico Provincial de Salamanca, sección de Protocolos, y corresponden a cartas dotales, arras, bienes que se aportan al matrimonio, inventarios, almonedas y testamentos. Añadimos a continuación las localidades de las que se conservan escrituras y años, primero y último en que aparecen representadas: Alberca, 1585-1806; Candelario, 1700-1873; Casas del Conde, 1760-1860; Cepeda, 16401859; Miranda del Castañar, 1584-1857 (Esta villa acoge también escrituras de los siguientes lugares: Aldea del Conde, Cabaco, Garcibuey, La Nava, Madroñal. Pinedas, Santibáñez y Zereceda). Mogarraz, solamente conserva documentación de 1863 a 1864. Monforte, 1755-1857; San Esteban, 1650-1660; San Martín, 1619, 1837; Santibáñez, año 1761 y perteneciente solo al Archivo Parroquial. Sequeros, 1638-1833; Sotoserrano, 15871857; Villanueva, 1757, 1835. 
El aprovechamiento de todas las fuentes documentales de un lugar o comarca no presupone sin más unas conclusiones representativas de toda la población; solo refleja la parte de vecinos que testaban. Los archivos nunca dan frutos iguales y a veces, como es el caso de Mogarraz, la escasez de documentación conservada se ve compensada con creces por la abundancia de las piezas-testigo.

Incorporamos al estudio de la Sierra de Francia el de Candelario - comarca y lugar arcaizantes en el campo de la indumentaria - para medir la intensidad en las variantes, hasta qué grado son perceptibles y qué elementos de contraste o identidad pueden establecerse entre pueblos vecinos y comarcas cercanas. Trajes como el de Vistas que se tenían por exclusivos de la Alberca y que perviven también en Mogarraz, abundan en documentos de Candelario.

Este trabajo trata de documentar la cruz como una de las piezas más constantes dentro de la joyería tradicional, que sobrevive unas veces abiertamente como fin en sí misma, otras, emboscada entre la guarnición como excusa decorativa, o reducida por los plateros, que repiten su motivo sin saberlo, a un tic de inercia; la cruz fue, a un tiempo, protección y adorno.

En ocasiones se presenta sola la cruz, en otras - menos- el crucifijo (en medallas, patenas y corazones de novia). La cruz se cruza a veces con las familias de las medallas, rosarios y relicarios y puede, además, hallarse representada en sortijas o tumbagas, hebillas y broches, botones, corazones, evangelios, relicarios, mediaslunas y otros dijes. Generalmente, la mayoría de las joyas llevan camuflada una cruz.

\section{IMPORTANCIA DE LOS PLATEROS SALMANTINOS EN EL SIGLO XV}

En 3 de julio del año 1489, por privilegio de los Reyes Católicos, los plateros de la ciudad de Salamanca quedaban eximidos de ciertas alcabalas a que estaban obligados por labrar oro y plata en sus tiendas, así como por la que compraban ya labrada.

Varias conclusiones se manifiestan en este documento: a) la existencia de un gremio poderoso de plateros, capaces de protestar contra los arrendadores de alcabalas. Esta exención se hacía extensiva a la Tierra de Salamanca y Ciudad Rodrigo, de donde tendremos noticias concretas en el siglo Xvi, y a las poblaciones serranas de cierto relieve como San Martín del Castañar, San Esteban de la Sierra y Miranda del Castañar, todas tres con una vecindad considerable de judíos, algunos de los cuales - conversos o no- trabajarían el oro y la plata ${ }^{3}$. b) La evidencia de un comercio importan-

3 Ver en Antonio CEA GutiérReZ, "La comunidad judía en la Sierra de Francia...", RDTP, XLIII (1988). 
te de materia prima que luego se trabajaba en los talleres salmantinos, aunque desconocemos las fuentes de las que se abastecían, y lo que compraban ya labrado. La estima que merecían en este siglo los plateros salmantinos queda patente en varios pasajes de la Real Cédula. En uno de ellos se atestigua el florecimiento y la abundancia de los talleres de estos plateros "que hacen y labran muchas prendas de platan. En otro, se alaba la maestría con "que saben de labrar cosas finas, polydas de oro e plata" ${ }^{4}$. Todo ello evidencia la calidad y personalidad de estos maestros de cuyas tiendas debieron salir ejemplares de primer orden. Debemos considerar pues la escuela de plateros de Salamanca como un foco importante, a cuya influencia no se sustraería la serranía de Francia.

En la tabla de plateros y maestros plateros que hemos podido establecer a partir del siglo XvI, quedan patentes dos cosas: por una parte, la corriente más o menos constante de plateros locales, naturales o avecindados, con un área de expansión que generalmente no traspasa su propia localidad y un saber que deja herencia como los Rosellón de Mogarraz, familia de plateros durante cinco generaciones. Por otra, el abastecimiento, ante la necesidad de obras de mayor envergadura, de maestros plateros de las ciudades circunvecinas, Salamanca, Béjar, Plasencia, Coria y Ciudad Rodrigo. En ambos casos, sean maestros locales o de la ciudad, se dan dos posibilidades: que tengan escuela o que trabajen solos.

Siglo XVI

Durante esta centuria encontramos en Miranda del Castañar varias obras del maestro platero Alonso Martín Rodrígues, avecindado en Salamanca.

Siglo XVII

Miranda del Castañar se sirve en la década de los 60-70, del maestro placentino Antonio Sánchez, quien al final traslada su taller a la ciudad de Salamanca.

Sotoserrano, entre los años 1610 y 1620 , encarga trabajos al platero de la catedral de Coria y en 1646, al platero de Béjar. Monforte en cambio, se inclina por los plateros de Ciudad Rodrigo, ordenando, entre los años 1620 y 1624, varios encargos al maestro Diego de Ribera.

En este siglo y como maestro local se destaca Pedro de Pedraça, platero de la villa de San Esteban de la Sierra, que trabaja entre 1627 y 1652 en San Esteban y Miranda del Castañar.

4 Archivo General de Simancas, R.G.S., VII, 1489 ff.356 y ss. 
Siglo XVIII

En este siglo la Sierra de Francia se inclina en sus encargos preferentemente por maestros salmantinos, entre los que destacan los Aillón: Manuel por los años treinta y Carlos Aillón entre 1750 y 1770.

La escuela cauriense aporta los trabajos de los maestros Juan Carterón en 1742 y Manuel Rubio en 1755 para Miranda. Aquí trabaja también el salmantino Bernardo, Fernando o Beroch Sánchez, conocido como «el Latonero", desde 1750 a 1760 .

Miguel Domínguez, platero bejarano, recibe por los años treinta, encargos en Sequeros.

Especial interés tiene en Miranda la escuela local de los Figueroa. En 1719 se cita trabajando en esa villa a Francisco Figueroa "el menor", lo que presupone la existencia de Francisco Figueroa "el Viejo", del que no se conservan noticias. Dicho Figueroa "el menor" recibía aún encargos en Miranda en el año 1740. Entre 1750 y 1759 le sucede en el trabajo Don Antonio Figueroa.

La escuela local que más se mantiene es la albercana, donde se documentan encargos "al platero de la Alberca" desde 1670. De nuevo hay encargos al platero de la Alberca en 1753, 1775, 1781 y 1794 , no solamente en esta localidad sino también en Miranda del Castañar donde ejecuta obras de cierto interés. Esta escuela albercana perdura a lo largo del siglo XIX hasta comienzos del $\mathrm{Xx}$ en que se extingue.

\section{Siglos XIX y XX}

Durante estos siglos la Sierra de Francia se sirve exclusivamente de maestros locales y de plateros de Salamanca, entre los que destaca por los años 1809-1832 Aureliano Ágreda con encargos en Herguijuela, Monforte y la Alberca. El platero salmantino Miguel Alejo Fuertes trabaja en Miranda en 1829, 1832-33-34-35 y 1836 consecutivamente.

La tradición de escuelas locales de plateros estaba ya muy depauperada a finales del siglo XIX. A comienzos del actual aún quedaba un platero en la Alberca. Hoy día se mantienen tres escuelas locales en Sequeros, Tamames y Mogarraz. Ejemplo espléndido de continuidad es el de la escuela mogarreña de los Rosellón, de procedencia extremeña. Ininterrumpidamente durante cinco generaciones han mantenido este arte recibiendo encargos de toda la serranía. Esta cantera de plateros u "oreros" se inicia con Rafael Rosellón Palomo, nacido por los años 50 del pasado siglo, y se continúa en su hijo Lorenzo Rosellón Prieto, a caballo entre los dos siglos. 
Sobre las recetas, patrones y librillos de estos dos plateros mogarreños se conservan dos manuales de Lorenzo y Rafael, con un muestrario de zarcillos, sortijas o tumbagas, cruces, medallas, etc., del mayor interés. En ellos se describen los utensilios de trabajo y sus medidas, división de las piezas, descripción y enumeración de sus elementos, "recetas de platiar", consejos que deben seguirse en las aleaciones y otras explicaciones de propia escuela.

Moisés Rosellón Cascón, al que entrevistamos en el año 75 con edad de 80 años, fue el tercero de la generación, del que aprendió su nieto Manuel Cascón Rosellón, que en realidad hace el número cinco de dicha generación de plateros; el cuarto recae en su madre que no recibió instrucciones en el oficio.

Centros o focos de maestros plateros no locales en la Serranía de Francia:

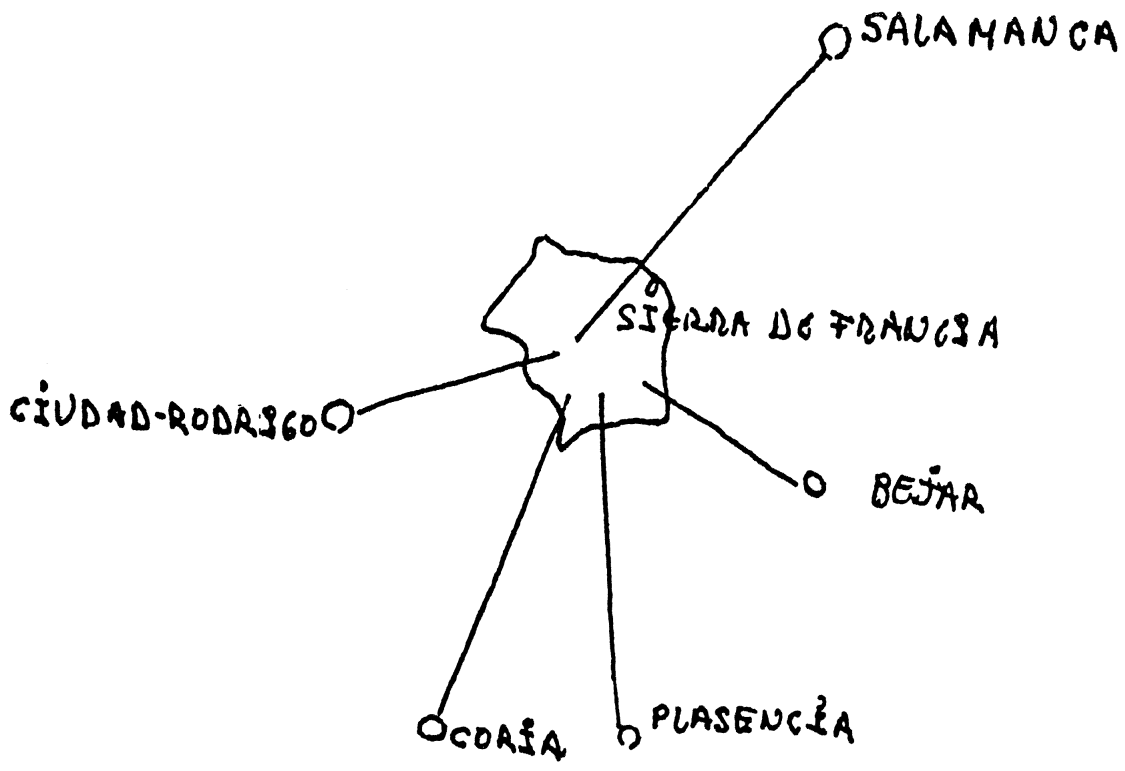

\begin{tabular}{|c|c|c|c|c|}
\hline LOCALIDAD & $X V I$ & $X V I I$ & $X V I I I$ & $X I X$ \\
\hline Salamanca . & \multirow{5}{*}{$\begin{array}{l}3 \\
1\end{array}$} & 1 & \multirow{5}{*}{$\begin{array}{r}13 \\
1\end{array}$} & \multirow[t]{5}{*}{12} \\
\hline Béjar .................... & & 1 & & \\
\hline Ciudad Rodrigo ....... & & 2 & & \\
\hline Coria & & 2 & & \\
\hline Plasencia ...... & & 2 & & \\
\hline
\end{tabular}




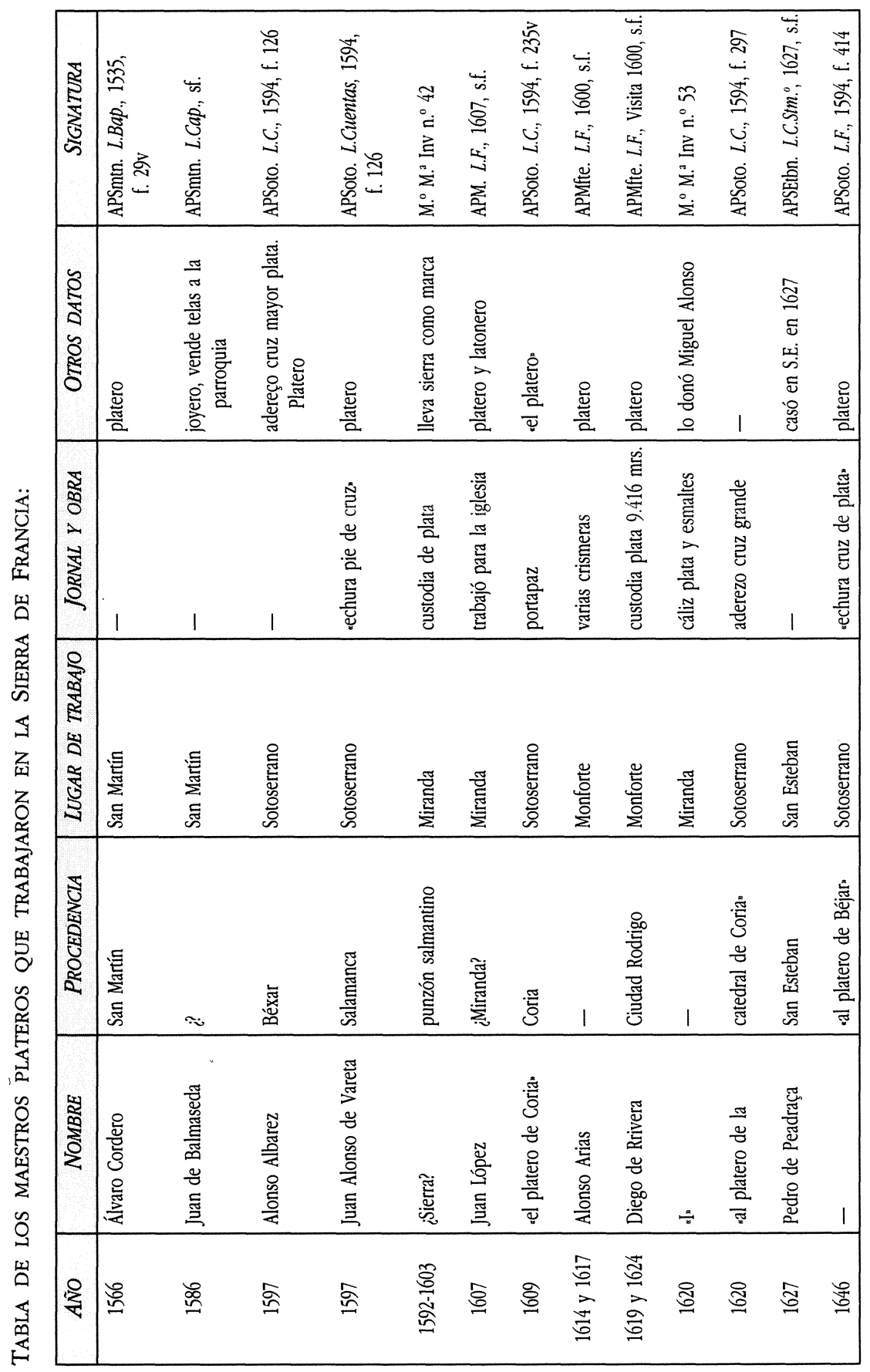




\begin{tabular}{|c|c|c|c|c|c|c|c|c|c|c|c|c|c|}
\hline 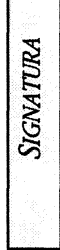 & 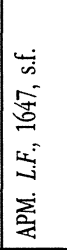 & 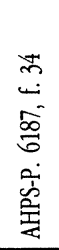 & 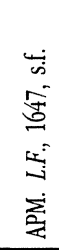 & 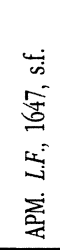 & 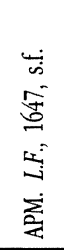 & 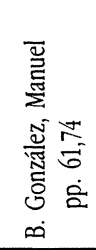 & 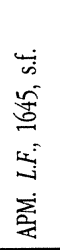 & 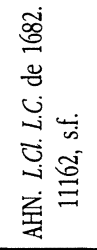 & 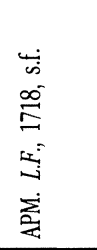 & 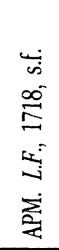 & 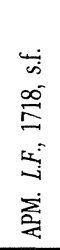 & 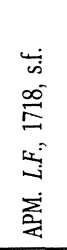 & 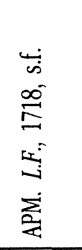 \\
\hline 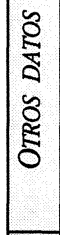 & 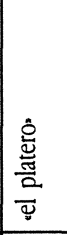 & $\begin{array}{l}\stackrel{8}{\frac{8}{2}} \\
\text { 总 }\end{array}$ & 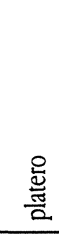 & 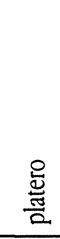 & 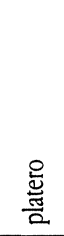 & 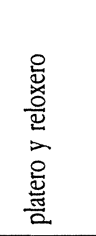 & 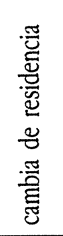 & 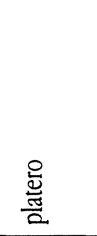 & 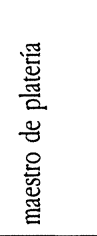 & 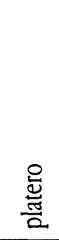 & 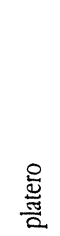 & 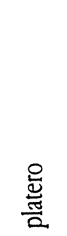 & 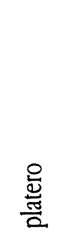 \\
\hline 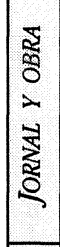 & 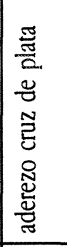 & 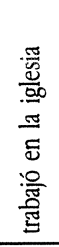 & 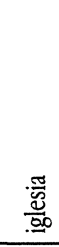 & 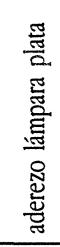 & 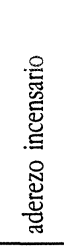 & 1 & 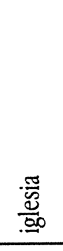 & 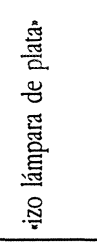 & 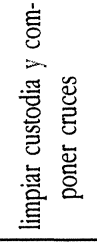 & 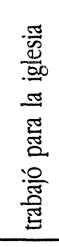 & 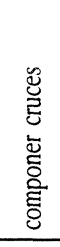 & 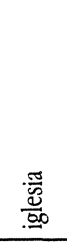 & 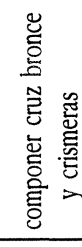 \\
\hline 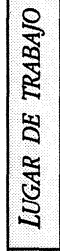 & $\begin{array}{l}\text { 莺 } \\
\text { 莺 }\end{array}$ & 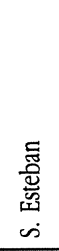 & $\begin{array}{l}\text { 莺 } \\
\frac{2}{2}\end{array}$ & $\begin{array}{l}\text { 苞 } \\
\text { 足 }\end{array}$ & $\begin{array}{l}\text { 莺 } \\
\frac{1}{2}\end{array}$ & 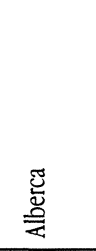 & $\begin{array}{l}\text { 思 } \\
\text { 竞 }\end{array}$ & 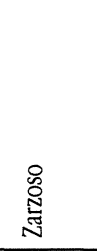 & 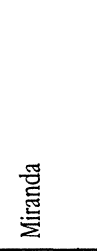 & $\begin{array}{l}\text { 莺 } \\
\text { 足 }\end{array}$ & $\begin{array}{l}\text { 莺 } \\
\frac{\pi}{2}\end{array}$ & 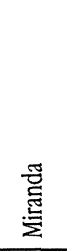 & 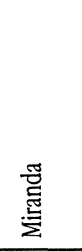 \\
\hline 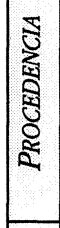 & 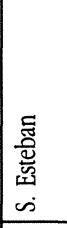 & 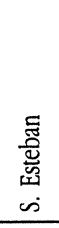 & 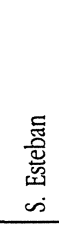 & $\begin{array}{l}\text { : } \\
\text { s. } \\
\text { s. } \\
\text { c } \\
\text { s. }\end{array}$ & 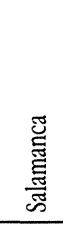 & 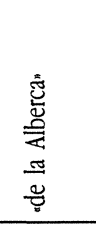 & 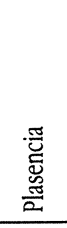 & 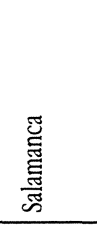 & 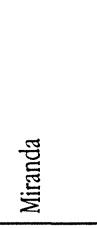 & 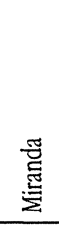 & 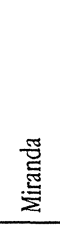 & 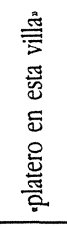 & 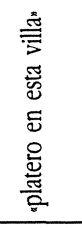 \\
\hline 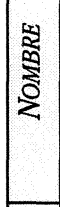 & 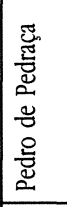 & 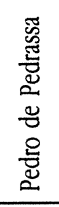 & 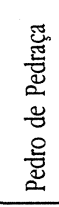 & 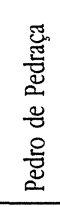 & 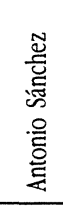 & 1 & 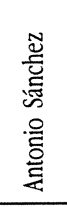 & 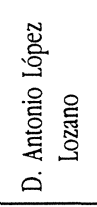 & 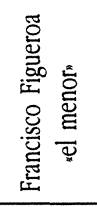 & 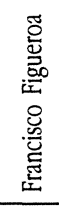 & 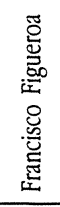 & 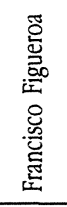 & 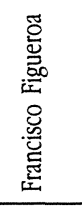 \\
\hline ; & 禺 & 吕 & చ్ర్ర & 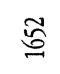 & 임 & 占 & 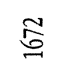 & $\stackrel{\Xi}{\Xi}$ & 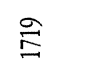 & $\underset{\Xi}{\mathbb{I}}$ & 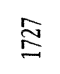 & $\stackrel{\infty}{\Xi}$ & $\stackrel{\overbrace{}}{\cong}$ \\
\hline
\end{tabular}




\begin{tabular}{|c|c|c|c|c|c|c|c|c|c|c|c|c|c|}
\hline 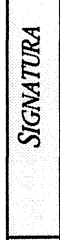 & 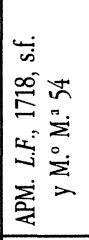 & 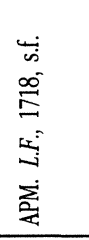 & 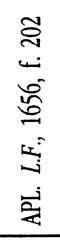 & 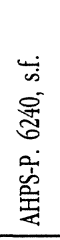 & 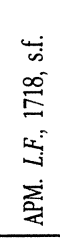 & 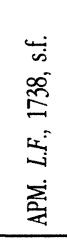 & 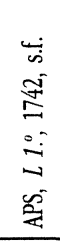 & 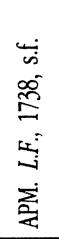 & 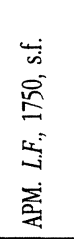 & 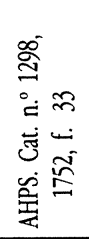 & 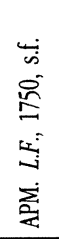 & 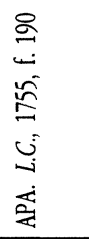 & 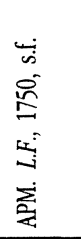 \\
\hline 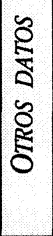 & 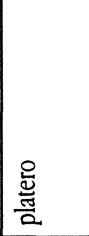 & 1 & 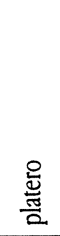 & 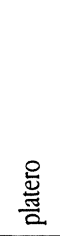 & 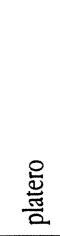 & 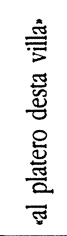 & 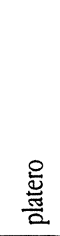 & 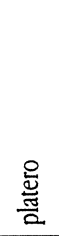 & $\begin{array}{l}\text { 忞 } \\
\text { 咅 }\end{array}$ & 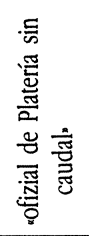 & 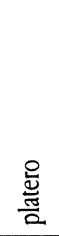 & 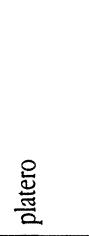 & 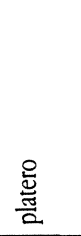 \\
\hline 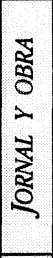 & 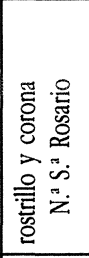 & 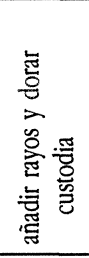 & 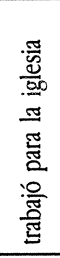 & 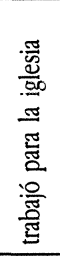 & 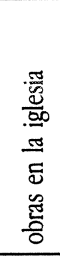 & 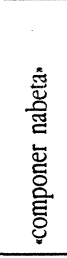 & 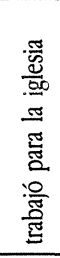 & 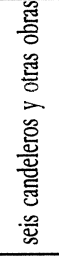 & 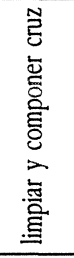 & 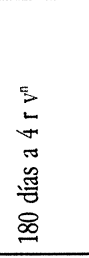 & 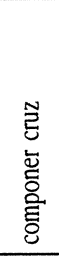 & 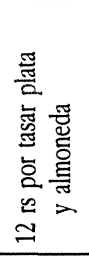 & 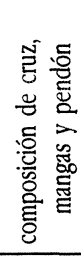 \\
\hline 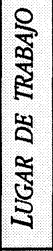 & \begin{tabular}{|l} 
\\
莺 \\
\end{tabular} & $\begin{array}{l}\text { 莺 } \\
\text { 总 }\end{array}$ & 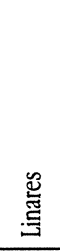 & 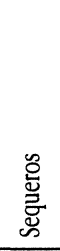 & $\begin{array}{l}\text { 莺 } \\
\frac{1}{2}\end{array}$ & 莺 & 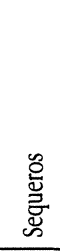 & $\begin{array}{l}\text { 莺 } \\
\text { 吾 }\end{array}$ & $\begin{array}{l}\text { 莺 } \\
\text { 莺 }\end{array}$ & 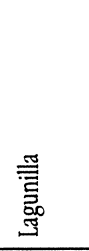 & $\begin{array}{l}\text { 莺 } \\
\text { 吾 }\end{array}$ & 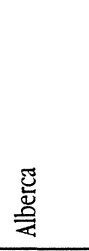 & $\begin{array}{l}\text { 莺 } \\
\text { 荧 }\end{array}$ \\
\hline 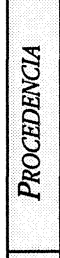 & 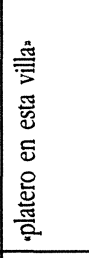 & $\begin{array}{l}\text { 莺 } \\
\text { 营 }\end{array}$ & 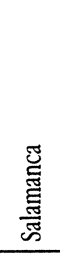 & 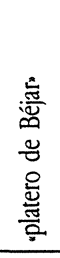 & $\begin{array}{l}\text { 苞 } \\
\end{array}$ & 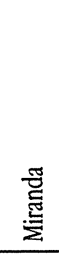 & 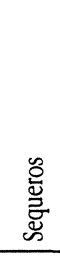 & 芯 & 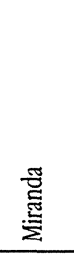 & 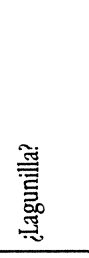 & 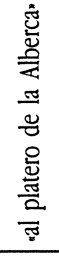 & 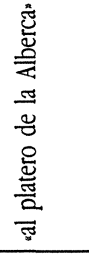 & 苟 \\
\hline 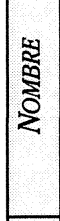 & 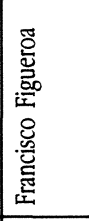 & 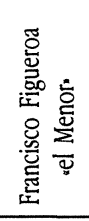 & 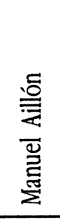 & 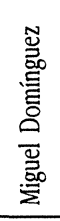 & 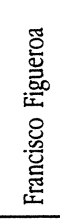 & 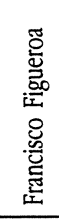 & 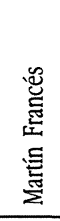 & 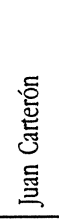 & 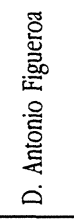 & 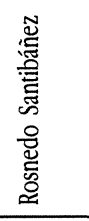 & 1 & 1 & 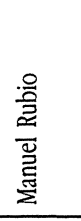 \\
\hline ; & $\widetilde{\widetilde{\Xi}}$ & $\cong$ & $\stackrel{\cong}{\cong}$ & 苋 & 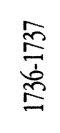 & 番 & I & 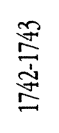 & 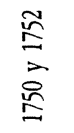 & $\widetilde{\Xi}$ & $\cong$ & 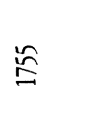 & 气气 \\
\hline
\end{tabular}




\begin{tabular}{|c|c|c|c|c|c|c|c|c|c|c|c|c|}
\hline 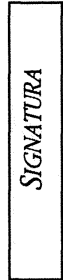 & 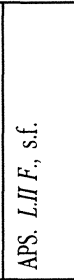 & 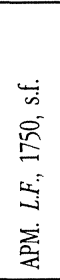 & 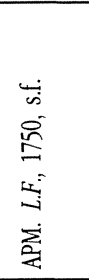 & 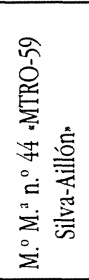 & 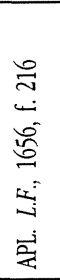 & 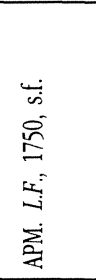 & 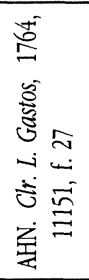 & 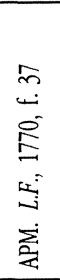 & 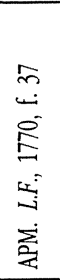 & 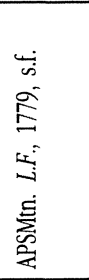 & 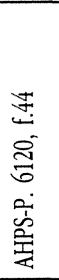 & 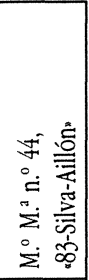 \\
\hline 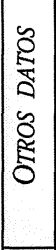 & 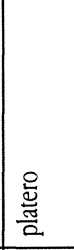 & 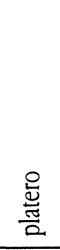 & 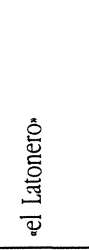 & 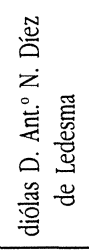 & $\begin{array}{l}\frac{8}{2} \\
\frac{\tilde{y}}{2}\end{array}$ & 1 & 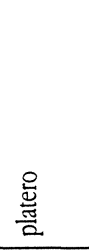 & 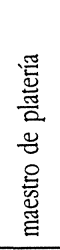 & $\begin{array}{l}\text { 总 } \\
\text { 农. }\end{array}$ & 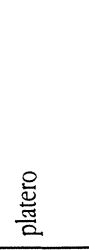 & $\begin{array}{l}\stackrel{\circ}{\frac{8}{2}} \\
\frac{\tilde{z}}{2}\end{array}$ & 1 \\
\hline 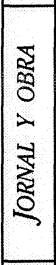 & 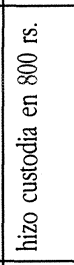 & 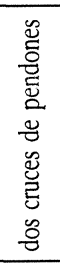 & 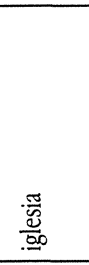 & 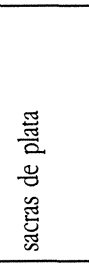 & 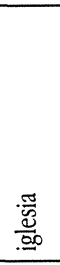 & 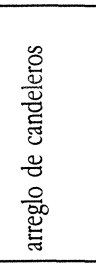 & 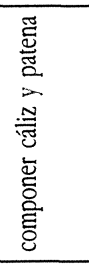 & 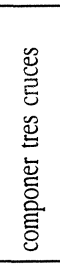 & 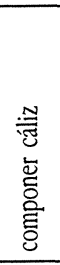 & 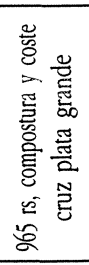 & 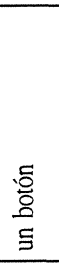 & 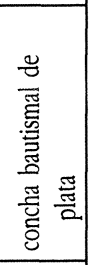 \\
\hline 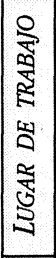 & 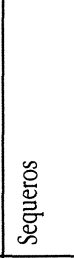 & $\begin{array}{l}\text { 㺃 } \\
\text { 离 }\end{array}$ & 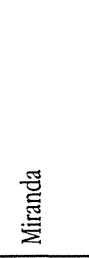 & $\begin{array}{l}\text { 莺 } \\
\text { 吾 }\end{array}$ & 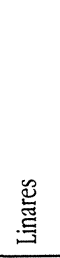 & 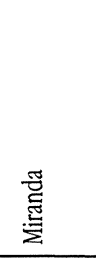 & $\begin{array}{l}0 \\
\text { 总 } \\
\text { 焉 }\end{array}$ & $\begin{array}{l}\text { 莺 } \\
\text { 焉 }\end{array}$ & $\begin{array}{l}\text { 莺 } \\
\text { 吾 }\end{array}$ & 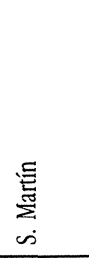 & 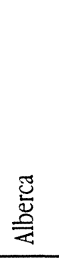 & $\begin{array}{l}\text { 莺 } \\
\text { 竞 }\end{array}$ \\
\hline 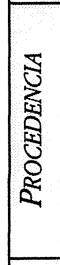 & 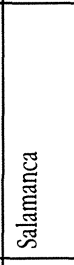 & 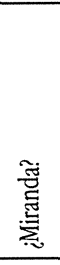 & 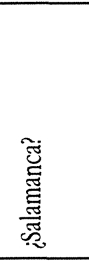 & $\begin{array}{l}\text { 芯 } \\
\text { 䓌 } \\
\text { 䭴 } \\
\end{array}$ & 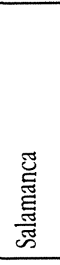 & 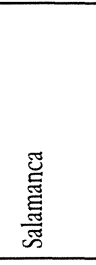 & 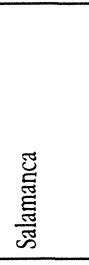 & 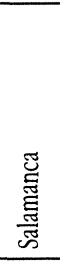 & $\begin{array}{l}\text { 芯 } \\
\text { 岸 }\end{array}$ & 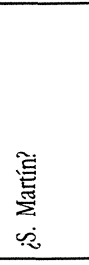 & 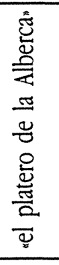 & 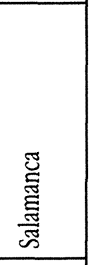 \\
\hline 贸 & 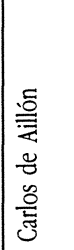 & 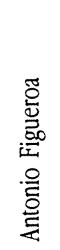 & 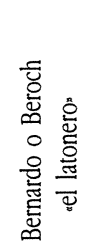 & 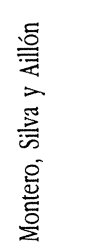 & 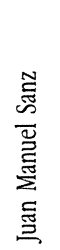 & 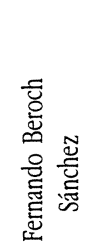 & 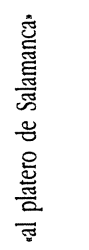 & 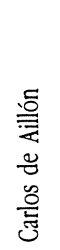 & 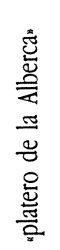 & 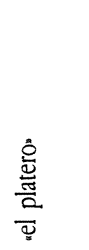 & 1 & 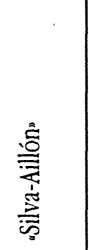 \\
\hline ; & $\underline{\underline{E}}$ & 佥 & 点 & 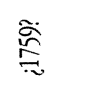 & $\stackrel{8}{g}$ & $\stackrel{\ddot{\mathrm{c}}}{\mathrm{a}}$ & $\stackrel{\mathrm{a}}{\mathrm{g}}$ & $\tilde{E}$ & $\stackrel{E}{E}$ & $\widehat{E}$ & $\stackrel{\overrightarrow{\underline{0}}}{=}$ & 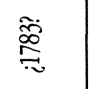 \\
\hline
\end{tabular}




\begin{tabular}{|c|c|c|c|c|c|c|c|c|c|c|c|c|}
\hline 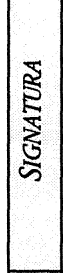 & 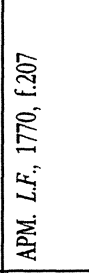 & 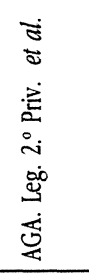 & 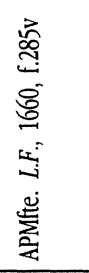 & 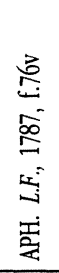 & 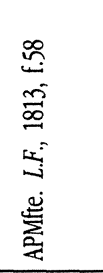 & 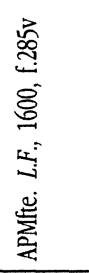 & 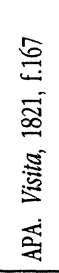 & 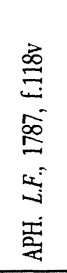 & 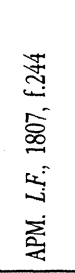 & 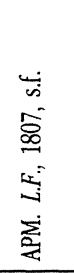 & 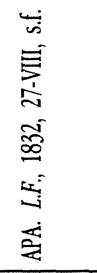 & 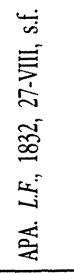 \\
\hline 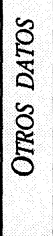 & 1 & 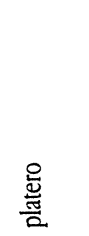 & 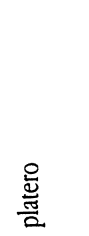 & 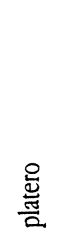 & 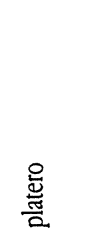 & 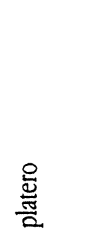 & 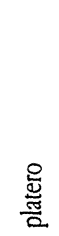 & 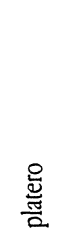 & 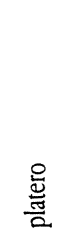 & 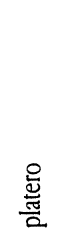 & $\begin{array}{l}\text { 总 } \\
\text { 胥 }\end{array}$ & 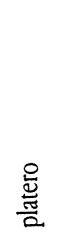 \\
\hline 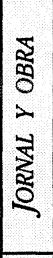 & 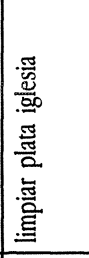 & 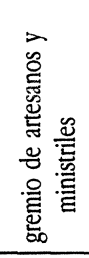 & 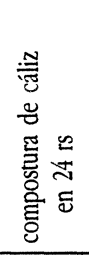 & 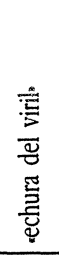 & 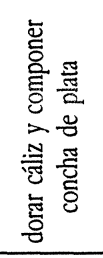 & 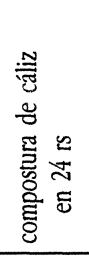 & 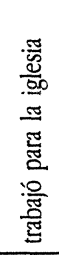 & 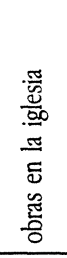 & 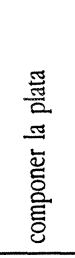 & 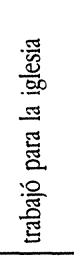 & 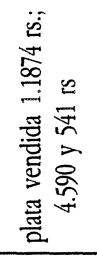 & 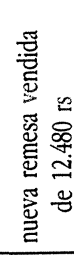 \\
\hline 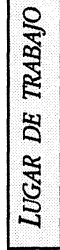 & 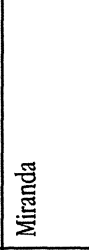 & 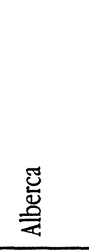 & 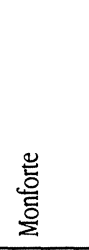 & 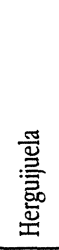 & $\begin{array}{l}\text { 芯 } \\
\text { 휼 }\end{array}$ & 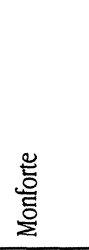 & 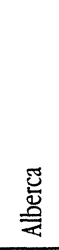 & 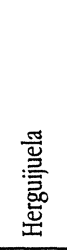 & $\begin{array}{l}\text { 㺃 } \\
\text { 焉 }\end{array}$ & 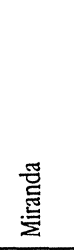 & 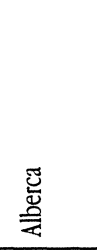 & 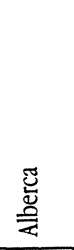 \\
\hline 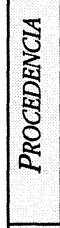 & 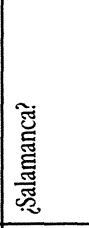 & 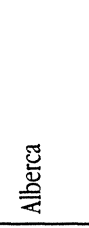 & 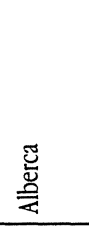 & 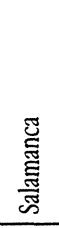 & 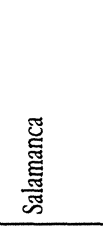 & 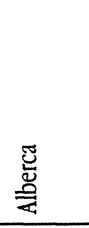 & 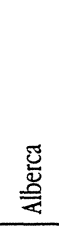 & 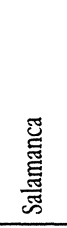 & 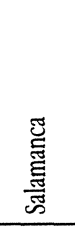 & 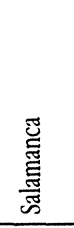 & 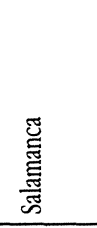 & 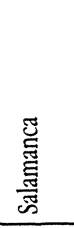 \\
\hline 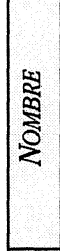 & 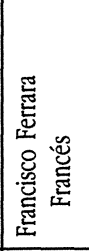 & 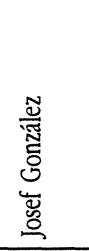 & 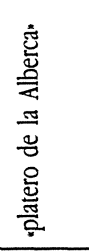 & 氶 & 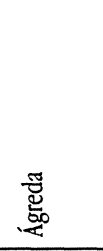 & 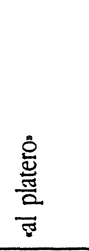 & 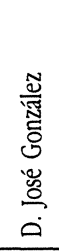 & 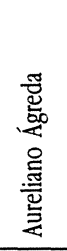 & 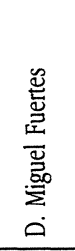 & 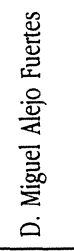 & 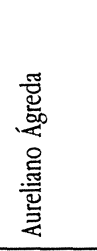 & 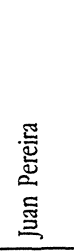 \\
\hline द्रे & 兽 & $\stackrel{\Delta}{\Xi}$ & 容 & 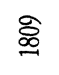 & $\stackrel{\stackrel{\partial े}{\sim}}{=}$ & 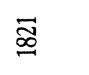 & $\stackrel{\bar{\Phi}}{\sim}$ & $\stackrel{\infty}{\mathscr{\Phi}}$ & ळ్ & $\underset{\widetilde{\otimes}}{\widetilde{\Omega}}$ & 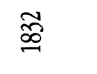 & 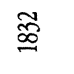 \\
\hline
\end{tabular}




\begin{tabular}{|c|c|c|c|c|c|c|c|c|c|c|c|c|c|}
\hline 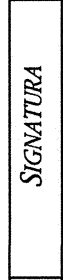 & 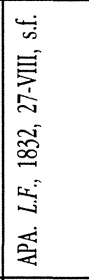 & 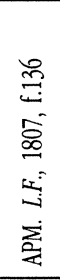 & $\begin{array}{l}\dot{\dot{s}} \\
\ddot{m} \\
\dot{m} \\
\dot{m} \\
\dot{m}\end{array}$ & 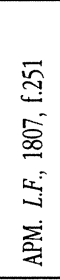 & 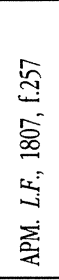 & $\begin{array}{l}\dot{j} \\
\dot{n} \\
\dot{\sim} \\
\dot{\omega} \\
\dot{\omega}\end{array}$ & & & & & & & \\
\hline 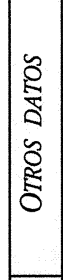 & 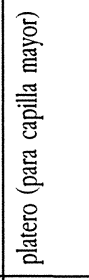 & $\begin{array}{l}\text { 总 } \\
\text { 咅 }\end{array}$ & 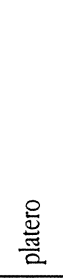 & $\begin{array}{l}\text { 总 } \\
\text { 言 }\end{array}$ & 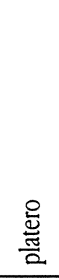 & 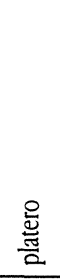 & 总 & 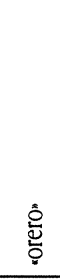 & 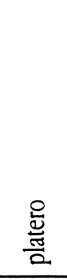 & 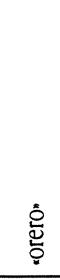 & 莺 & 总 & : \\
\hline 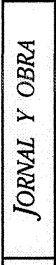 & 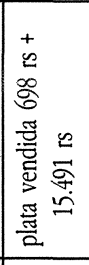 & 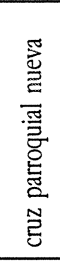 & 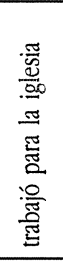 & 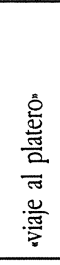 & 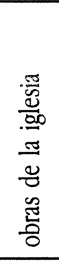 & 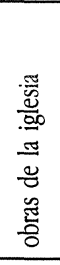 & 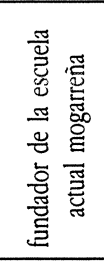 & 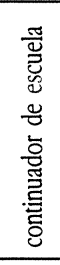 & 1 & 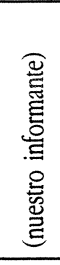 & 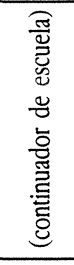 & 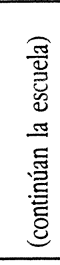 & 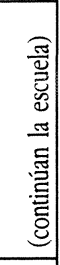 \\
\hline 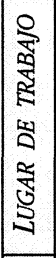 & 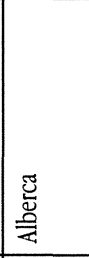 & 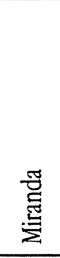 & 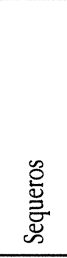 & $\begin{array}{l}\text { 㺃 } \\
\text { 荧 }\end{array}$ & 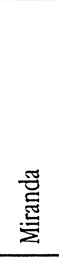 & 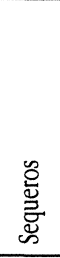 & 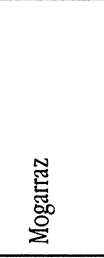 & 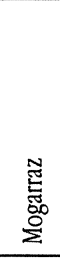 & 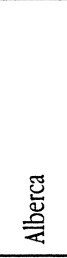 & 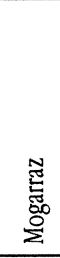 & 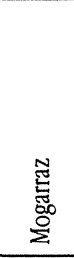 & 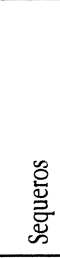 & 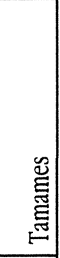 \\
\hline 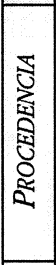 & 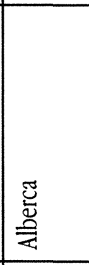 & 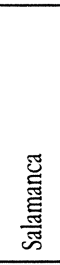 & 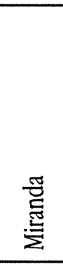 & 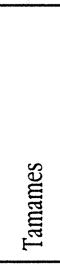 & 1 & 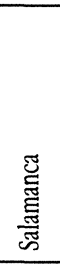 & 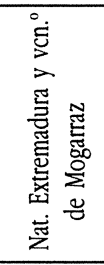 & 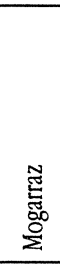 & 惡 & 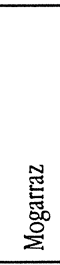 & 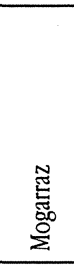 & 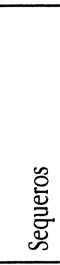 & 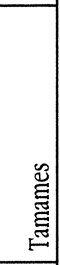 \\
\hline 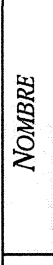 & 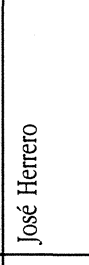 & 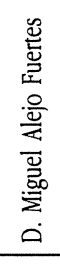 & 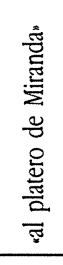 & 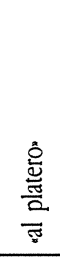 & 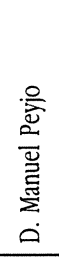 & 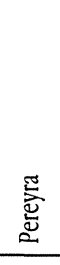 & 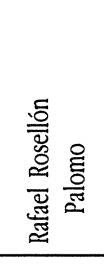 & 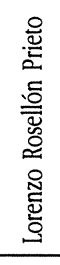 & 1 & 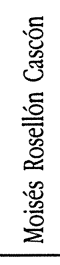 & 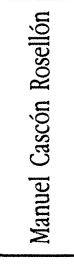 & 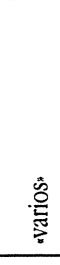 & 产 \\
\hline 害 & $\stackrel{\widetilde{\Xi}}{\stackrel{\approx}{\oplus}}$ & $\begin{array}{l}\stackrel{0}{\infty} \\
\stackrel{\infty}{1} \\
\underset{\infty}{\infty}\end{array}$ & 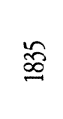 & $\approx$ & 怘 & 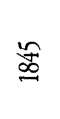 & 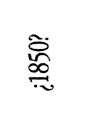 & : & $\tilde{\Xi}$ & $\begin{array}{l}\stackrel{\alpha}{\circ} \\
\stackrel{\delta}{\sigma}\end{array}$ & $\begin{array}{l}\text { よ } \\
\stackrel{\vec{\Xi}}{\Xi}\end{array}$ & $\stackrel{2}{\circ}$ & 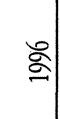 \\
\hline
\end{tabular}


Presentamos a continuación el Índice de las Cruces y sus advocaciones, número de piezas, y fechas primera y última en que aparecen documentadas:

\begin{tabular}{|l|c|l|r|}
\hline SIGLO & FECHA & & NOMBRE \\
\hline XVI & 1598 & Cruz & 1 \\
XVII & 1633 & Cruz & 50 \\
XVII & 1669 & Caravaca & 7 \\
XVII & 1685 & Santo Oficio & 1 \\
XVII & 1687 & Santo Toribio & 5 \\
XVIII & 1701 & Cruz & 204 \\
XVIII & 1701 & Caravaca & 32 \\
XVIII & 1700 & Santo Toribio & 16 \\
XVIII & 1702 & Lignumcrucis & 29 \\
XVIII & 1705 & Jerusalén & 9 \\
XVIII & 1730 & Oviedo & 32 \\
XVIII & 1736 & Burgos & 17 \\
& fecha última & & \\
XIX & 1872 & Cruz & 139 \\
XIX & 1823 & Santo Toribio & 4 \\
XIX & 1861 & Caravaca & 9 \\
XIX & 1830 & Lignumcrucis & 6 \\
XIX & 1832 & Jerusalén & 1 \\
XIX & 1806 & Oviedo & 1 \\
XIX & 1825 & Burgos & 15 \\
XIX & aparecen & & \\
XIX & 1819 & Valencia & 4 \\
\hline
\end{tabular}

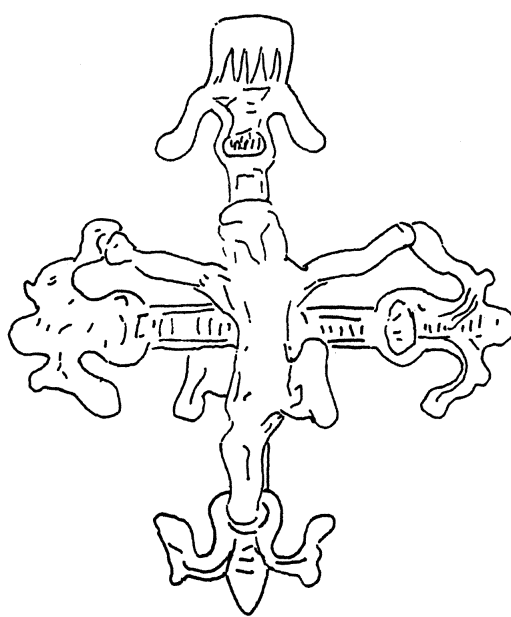

FIG. 1.-Crucifijo "de metal", conocido en el Reino de León como cruceta. Bello ejemplar y la más antigua joya-testigo que conocemos en su género. Parece cercana a las cruces procesionales góticas de carácter popular. Aún están frescos los patrones en los que se inspira con una tradición de nielados y alveolados en el nacimiento de cada lirio que sirve de extremo al palo y los brazos - casi igualesy fuerza a clavar las manos en la parte superior de los pétalos. El perizonium, a dos bandas, mesura la figura de Cristo. Labor a martillo. Sirve como extremo a una vueltita de corales (Museo del Pueblo Español, proc. de la Alberca). Podría catalogarse como pieza arcaizante, quizá de comienzos del siglo XVI. 


\section{SIGLO XVII}

\section{Las cruces}

No hay noticias documentadas en estas comarcas serranas sobre el apasionante tema de las cruces-joya, sus diversas formas y advocaciones hasta el siglo XVII, salvo un único texto en Sotoserrano, correspondiente al año 1598, donde escuetamente se cita "una cruzitan. Ni se habla de la materia de la que está compuesta, ni de su forma y guarnición, o si tiene advocación concreta. (AHPS-P 6287, f.166)

Bellísimas explicaciones y abundantes nos proporciona, en cambio, el siglo XVII. Siete localidades de la Sierra de Francia, en cuarenta documentos, arrojan luz sobre los tipos de cruces, sus elementos, nombres, material, etc.

LUGARES, CANTIDAD Y AÑO PRIMERO Y ÚLTIMO EN QUE SE REGISTRAN:

\begin{tabular}{|l|c|c|}
\hline \multicolumn{1}{|c|}{ LOCALIDAD } & PIEZAS & AÑOS \\
\hline San Martín & 5 & 1633,1697 \\
Cepeda & 16 & 1640,1694 \\
Miranda & 2 & 1645,1654 \\
San Esteban & 1 & 1651 \\
Sotoserrano & 3 & 1651,1680 \\
Sequeros & 11 & 1657,1699 \\
Alberca & 2 & 1685,1688 \\
\hline
\end{tabular}

MATERIAL DE QUE SE COMPONEN Y VOCES CON QUE SE DENOMINAN ${ }^{\text {s: }}$

\begin{tabular}{|l|l|l|}
\hline \multicolumn{1}{|c|}{ MATERIAL } & \multicolumn{1}{|c|}{ LOCALIDAD } & \multicolumn{1}{|c|}{ AÑOS } \\
\hline plata & (3) Sequeros & 1655,1685 \\
plata & (1) Alberca & 1688 \\
plata & (1) Cepeda & 1694 \\
plata ahumada & (1) Sotoserrano & 1665 \\
ahumada de oro & (1) Sequeros & 1663 \\
plata dorada & (1) San Martín & 1633 \\
plata dorada & (1) San Esteban & 1651 \\
sobredorada & (1) Sequeros & 1663 \\
dorada & (1) Cepeda & 1657 \\
\hline
\end{tabular}

5 Mantenemos las variantes sinónimas: plata abumada, abumada de oro, plata dorada, dorada, y sobredorada. 


\begin{tabular}{|l|l|l|}
\hline \multicolumn{1}{|c|}{ MATERIAL } & \multicolumn{1}{|c|}{ LOCALIDAD } & \multicolumn{1}{|c|}{ AÑOS } \\
\hline oro & (1) Cepeda & 1657 \\
oro & (1) San Martín & 1671 \\
oro & (1) Sequeros & 1698 \\
alambre & (1) Cepeda & 1686 \\
bronce & (1) Sequeros & 1699 \\
peltre & (1) Cepeda & 1649 \\
madera y peltre & (1) Cepeda & 1649 \\
vidrio & (1) Miranda & 1654 \\
marfil & (1) Cepeda & 1682 \\
\hline
\end{tabular}

CANTIDAD MÁXIMA DE CRUCES POR PERSONA Y PESO QUE ALCANZAN:

Dos cruces, respectivamente, en Cepeda, San Martín y Sequeros. Se explicita el peso en Cepeda: “[...] Xto de plata dorada de peso de dos onzas 20 rs" (1657).

El mayor número de cruces tiene el "crucifixo" en medio, en otros casos se sustituye el cristo, adoptando la cruz forma de relicario o viril.

TAMAÑOS DE LA CRUZ:

\begin{tabular}{|l|c|l|l|}
\hline \multicolumn{1}{|c|}{ TAMAÑOS } & PIEZAS & \multicolumn{1}{|c|}{ LOCALIDAD } & \multicolumn{1}{|c|}{ AÑOS } \\
\hline pequeña & $(3)$ & Cepeda & 1648,1682 \\
pequeña & $(3)$ & Sequeros & 1663,1699 \\
grande & $(1)$ & Cepeda & 1654 \\
ancha & $(1)$ & Cepeda & 1686 \\
\hline
\end{tabular}

DOCUMENTOS DONDE SE CITA EL CRUCIFIJO COMO ELEMENTO:

\begin{tabular}{|c|l|l|}
\hline PIEZAS & \multicolumn{1}{|c|}{ LOCALIDAD } & \multicolumn{1}{c|}{ AÑOS } \\
\hline 11 & Sequeros & 1651,1680 \\
9 & Cepeda & 1649,1694 \\
3 & San Martín & 1633,1697 \\
3 & Sotoserrano & 1651,1680 \\
1 & Alberca & 1685 \\
1 & San Esteban & 1651 \\
\hline
\end{tabular}

ELEMENTOS DE LA CRUZ EN ESTE PERÍODO:

Crucifijo.-El crucifijo puede ser de bulto lleno, vano o bueco ${ }^{8}$ (esta última variante se reconoce en los ejemplos donde aparece, como "mala o de alambren).

6 «i crufxo de peltre a modo de plata".

7 "Cruz de madera i cfxo de peltre".

8 El bulto lleno equivale al bulto redondo y hechura exenta. El bulto vano, a la media hechura o solo frontal, quedando la espalda o parte posterior hueca. 


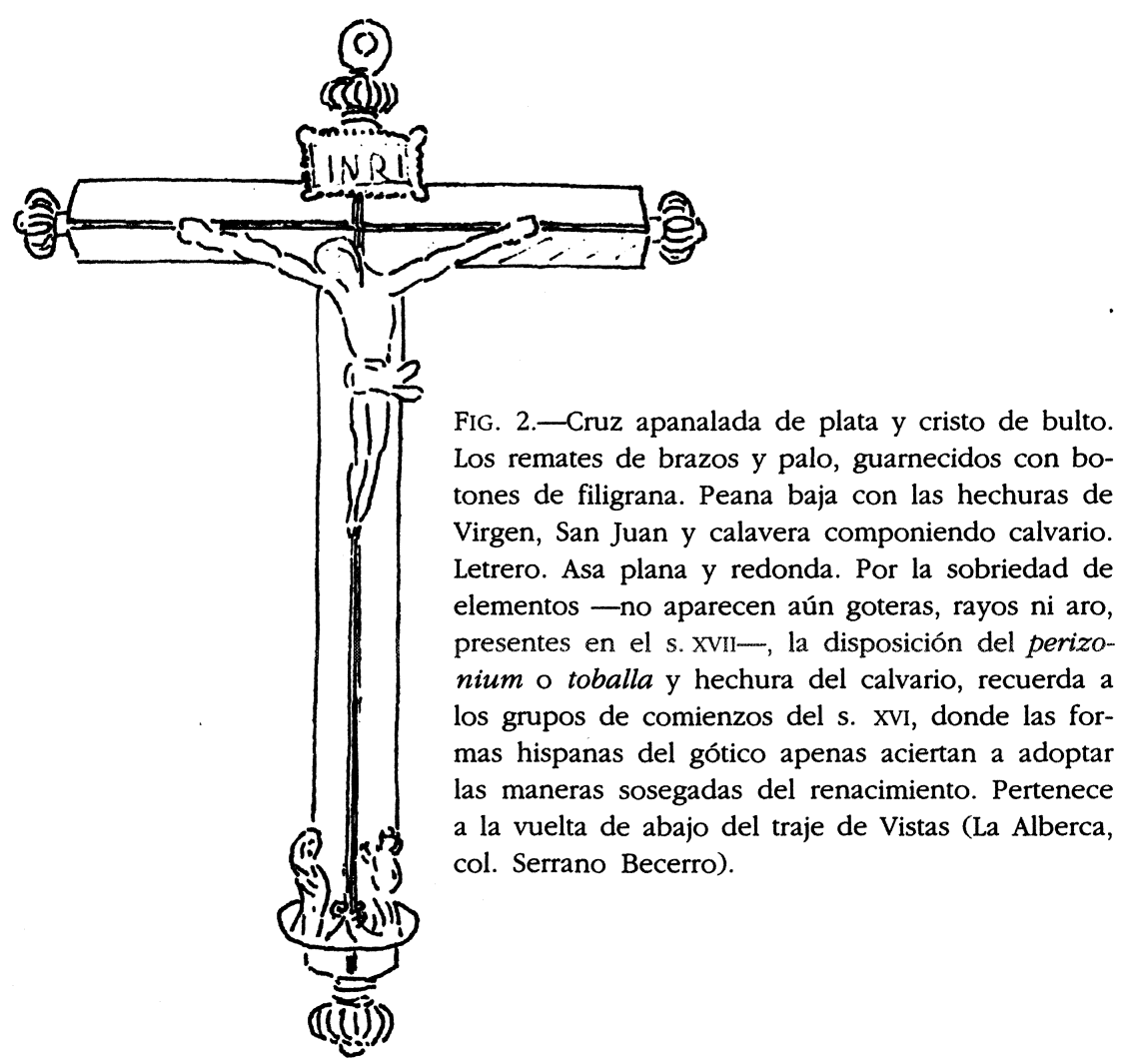

- Apanalado: "xto apanalado aumado de oro" ${ }^{9}$ (Sequeros, AHPS-P 6227, ff.69 y ss.).

- Vano o bueco: "xto de alambre malo bano ancho" (Cepeda, 1686. AHPS-P 5992, f.167).

- Pintado y embutido: "Crxto de bronze pequeño, la echura pintada en cruz y la cruz embutida" ${ }^{10}$ (Sequeros, 1699 AHPS-P 6235, f.12v y ss.).

Lados o brazos: De ellos penden con frecuencia remates o goteras, una de cuyas variantes tiene forma de higa. Otras veces, colgando de los brazos y el palo de la cruz, medallas. En realidad hay que incluir aquí no solo la pieza horizontal - brazos - sino la vertical o palo, a veces subdividida también en palo alto y palo bajo.

9 En realidad se está aludiendo aquí a la forma romboidal y no esquinada de la cruz - palo y brazos-, no al crucifijo.

10 Se supone que va insertada en otra cruz mayor de madera, o en una caja o vidriera, a manera de reliquia. 
Goteras: "con sus goteras de plata a los lados en forma de higas q pesarán como una onzan. Sequeros, 1699 (AHPS-P 6235, f.380).

Medallas: “[...] unas medallas a los brazos". Alberca, 1688 (AHPS-P 6143, f.23).

Remate o Encima: Estos remates suelen terminar en una filigrana abalaustrada: "cruz de bidrio y por remate una rosa encima". Miranda, 1654 (APM Inv. Rosario de 1657 s.f.).

Letras: "Cruz pequeña con unas letras que dicen: Hoc salutis opus, 1.000 mrs". Lo habitual es el letrero con el INRI: Iesus, Nazarenus, Rex, Iudeorum. Las letras o letrero va colocado encima del aro y bajo el remate. Cepeda, 1648 (AHPS-P 5982, f.65).

Aro: $\mathrm{El}$ aro o nimbo va colocado en torno a la cabeza de Cristo o supliéndolo si la cruz no lleva crucifijo: "Crucifixo con aro de lata". Alberca, 1685 (AHPS-P 6193, f.30).

Peana: A los pies de Cristo y sosteniéndolos va la peana. A veces, en su lugar o sobre ella, una calavera o una Concepción. En una cruz albercana del año 1638 , la peana lleva como adorno una concha o botón: "cruz de filigrana de plata con dos medallas de plata a los brazos y una concha y botón a la peana, 15 rs" (AHPS-P 6143, f.123v).

Argolla: En la parte superior la cruz tiene un aro o argolla que la une a la cadena: "Crucifixo con su argolla $60 \mathrm{rs".} \mathrm{Sotoserrano,} 1651$ (AHPS-P 6294, f.146).

Viriles o Relicario: Si la cruz es de relicario y no lleva crucifijo se ocupan los brazos y el palo con viriles, cristaleras o vidrieras, donde van embutidas las reliquias: "cruz de relicario con sus veriles $6 \mathrm{rs}$ ". Cepeda, 1657 (AHPS-P 5984, ff.90-103v).

LAS LABORES EN LA CRUZ:

La filigrana: "cruz de filigrana de plata". Alberca, 1688.

Los esmaltes: "Cristo con encomienda de oro esmaltada". Sequeros, 1698 (AHPS-P 6234, f.260).

Los engastes: "cruz engastada de plata". Es la acepción más desdibujada con labores que no se definen. Cepeda, 1666 (AHPS-P 5986, ff.23-25v).

PRECIOS MÁXIMO Y MÍNIMO EN QUE OSCILAN LAS CRUCES:

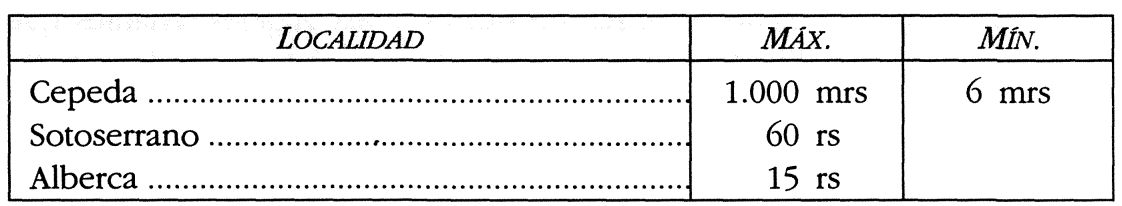




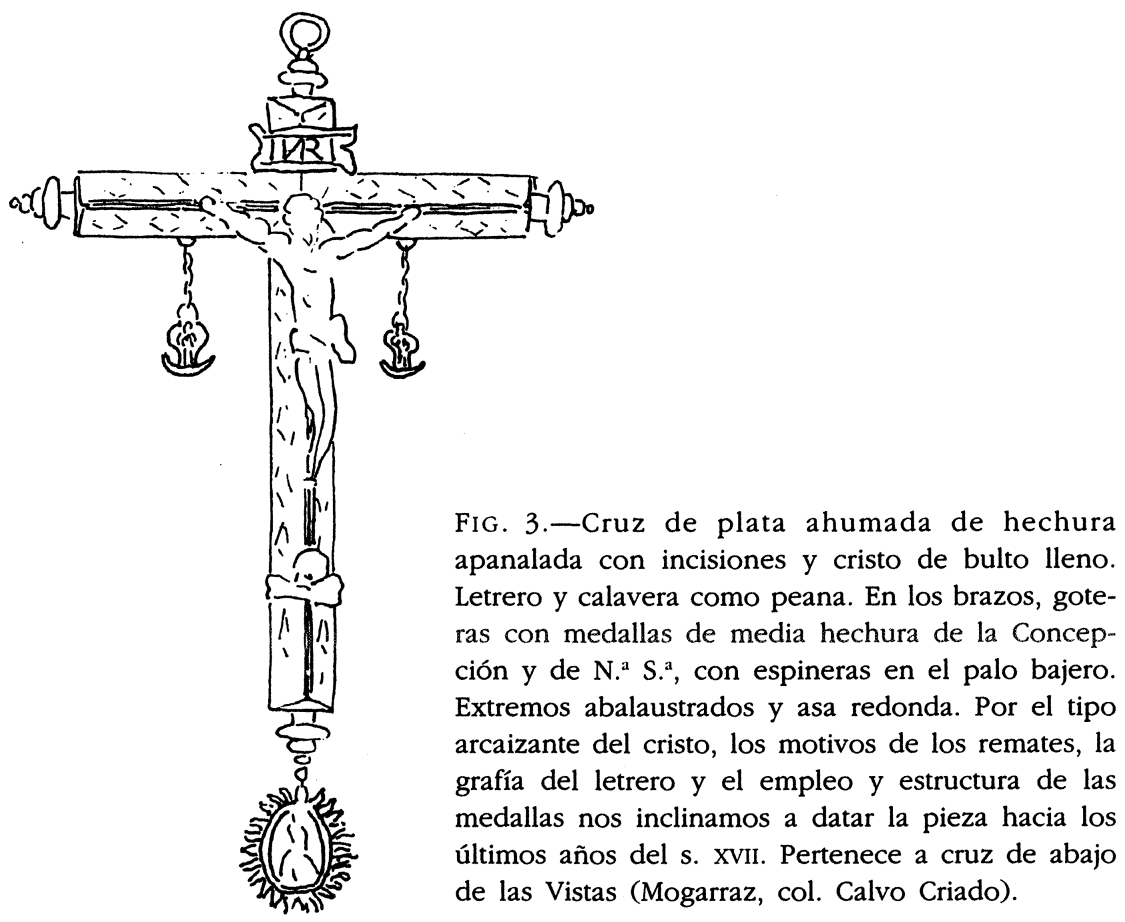

\section{ADVOCACIONES}

A. CARAVACA.-En el año 1669 aparece documentada por primera vez la cruz de Caravaca con siete ejemplares en el siglo xvil en las localidades de Cepeda y San Martín.

\begin{tabular}{|l|c|l|c|}
\hline \multicolumn{1}{|c|}{ LOCALIDAD } & PIEZAS & \multicolumn{1}{|c|}{ MATERIAL } & \multicolumn{1}{c|}{ AÑOS } \\
\hline San Martín & 2 & plata & 1669,1674 \\
Cepeda & 5 & alquimia & 1680,1691 \\
\hline
\end{tabular}

De una de estas cruces se dice que es pequeña o "cruzita". Cepeda, 1669 (AHPS-P 6189, f.76v). Otra iba dentro de una "caxa de plomo". San Martín, 1674. Una tercera formaba parte de "hilo de corales falsos". Cepeda, 1669. No se habla para nada en esta centuria del elemento más característico de esta cruz, el doble orden de brazos y los ángeles tenantes que la enriquecen, o si llevaba a los lados las figuras del sol, la luna y las estrellas, como es costumbre en esa figura. El número de cruces que encontramos con esta advocación, en documentos pertenecientes a una misma persona, llega a dos y aparece escrita como Carabaca. 

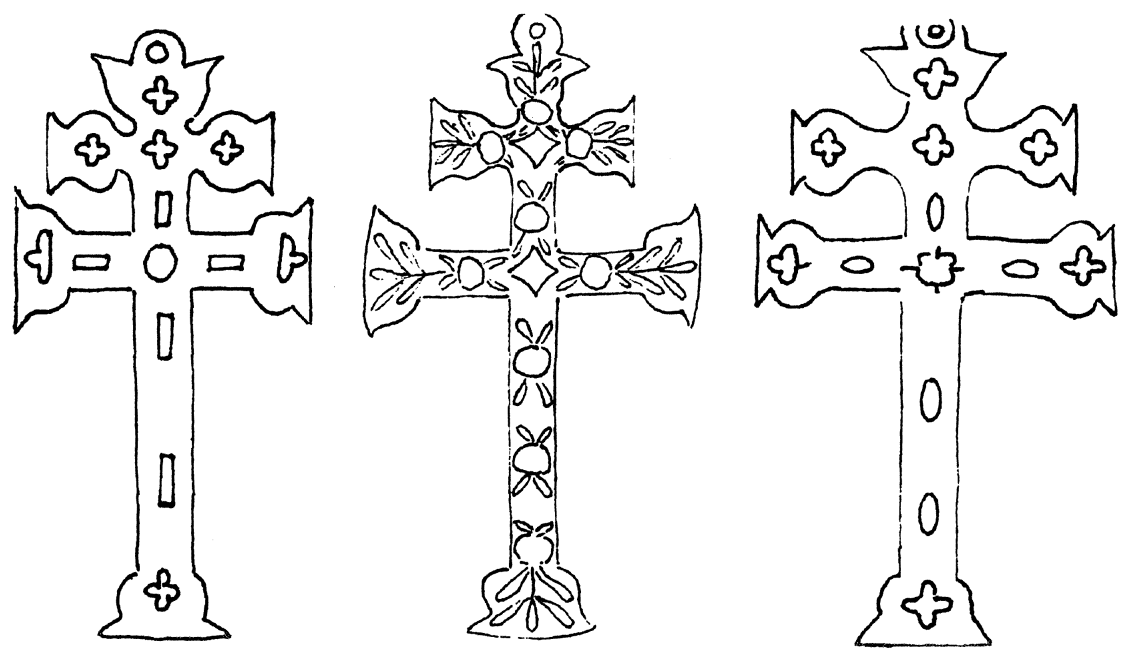

FIG. 4.-Cruces de Caravaca: a) cruz de "alquimia" que forma parte como extremo de un rosario. Brazos dobles y palo, recortados. En el enmedio botón hueco y en los extremos, pequeñas cruces treboladas y otras en forma de cruz latina. Los remates terminan en silueta de granada abierta (La Alberca, col. Puerto Hernández). b) Caravaca de "alquimia" perteneciente a dijero de niño (falta una de las caras). Brazos dobles y labores de granadas floridas en brazos y palo; el mismo motivo se siluetea en los extremos. El enmedio de ambos órdenes con huecos en rombo para acoger reliquias (La Alberca, col. de los Hoyos Puerto. c) Cruz de "metal" perteneciente a brazaleras. Palo y brazos dobles, recortados y motivos de alveolos y cruces treboladas; los extremos en granada abierta (Mogarraz, col. Calvo Cascón). Ninguno de los tres modelos tiene hechura alguna de Cristo o N. ${ }^{a}{ }^{3} .^{a}$ en el medio, ni las figuras del sol y la luna, ni anagramas de Jesús y María, tampoco ángeles tenantes, elementos todos característicos de las cruces que se documentan en el siglo XVIII, entre 1730 y 1778. Estas piezas-testigo se corresponden, en cambio, con ejemplos inventariados entre 1669 y 1691 , y entre 1801 y 1861. Parece más lógico que de ser obra del siglo XIX - siendo esta una comarca arcaizante- siguieran los esquemas del siglo anterior, aunque fuera de una manera fría y degenerada. Nos inclinaríamos, pues, por una datación en torno a la segunda mitad del siglo xviI.

B. CRUZ DE SANTO TORIBIO.-Cinco documentos pertenecientes a Sequeros, Sotoserrano y Cepeda hacen referencia a la cruz de Santo Toribio.

\begin{tabular}{|c|c|c|}
\hline LOCALIDAD & PIEZAS & $A \tilde{N} O S$ \\
\hline Sotoserrano .. & 1 & 1673 \\
\hline Sequeros........... & 3 & 1687,1696 \\
\hline Cepeda & 1 & 1698 \\
\hline
\end{tabular}

De las características y forma de esta cruz apenas se concreta nada sobre si era maciza o hueca ni si contaba con ánima para embutir dentro 
reliquias o un lignumcrucis. Solo se enumeran los extremos de brazos y palo que conocemos por remates. En uno de los documentos se cita "Cruz de Santo Toribio con los remates de plata". Sequeros, 1687 (AHPS-P 6230, f.8 y ss.). En el mismo protocolo y año (f.56) se documenta en Sequeros otra "cruz de santo Toribio con remate de plata". Es de suponer que de llevar un solo remate, fuera el del palo inferior, de no llevarlo también en los brazos, puesto que el palo cimero iría directamente unido a la argolla de la cadena. En Cepeda, año 1698, contamos con "un St. ${ }^{\circ}$ Toribio con tres remates engastados en plata" (AHPS-P 5995, f.141). Ocuparían estos los brazos y palo inferior de la cruz. La labor de engaste, a diferencia de la de filigrana, suele ser lisa o "a martillo".

El material de que se componían era en parte la plata, como hemos visto en los extremos de brazos y palo, lo cual supone otro que no se expresa, como la madera o las vidrieras si contenían reliquias. Solamente en uno de los tres documentos de Sequeros se describe sin más como de plata, generalizando este material o incluyéndolo en su totalidad.

Tirso en su obra La Peña de Francia, menciona la cruz de St. ${ }^{\circ}$ Toribio, entre otras joyas, como pieza habitual de las serranas:

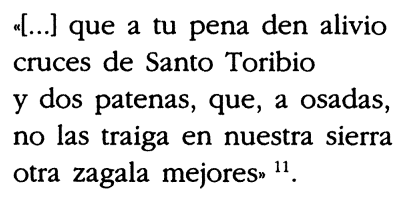

11 (Acto III, p. 1872) Cito por la edición de B. de los Ríos. Es evidente que Tirso se refiere en este caso a la serranía de Francia. En otros autores "la manera serrana - posiblemente no sólo de esta sierra sino de todas- aparece como diferenciante y espontánea generadora de variantes propias en la indumentaria femenina. Desde luego, la de Francia las ha mantenido bien específicas hasta hoy, desde la fosilización del traje, respecto al resto de las comarcas salmantinas. En el Libro de Buen Amor se dice: "darte he joyas de sierra" (Serranas, 955; ed. de J. Corominas). Vélez de Guevara comenta: «la Serrana [...] vestida a lo serrano de muger, con saiuelo y muchas patenas, el cabello tendido y una montera con plumas" (cito por T.A.E, I, 30). Cervantes: "Galatea [...] venía vestida a la serrana, con los luengos cabellos sueltos al vienton. La Galatea, I, 753 (cito por A. Valbuena). De nuevo Tirso, páginas más abajo, dice: «cuentas, corales, patenas/ y un tocado a lo serrano" (Acto III, p. 1875). Existe una doble clasificación por tendencias, según el estilo personal de vestir, siguiendo los vaivenes de la moda - $\rightarrow$ uso de ciudadanos - o bien, manteniendo las ya fosilizadas - - al estilo del país", o "según se acostumbra gastar en mi lugar"- Dentro de los modelos arcaizantes los textos literarios distinguen entre: el traje "a lo villano", "a lo serrano" y "a uso de labradores", sin contar la manera "gitana", siempre abigarrada de esa minoría marginal 


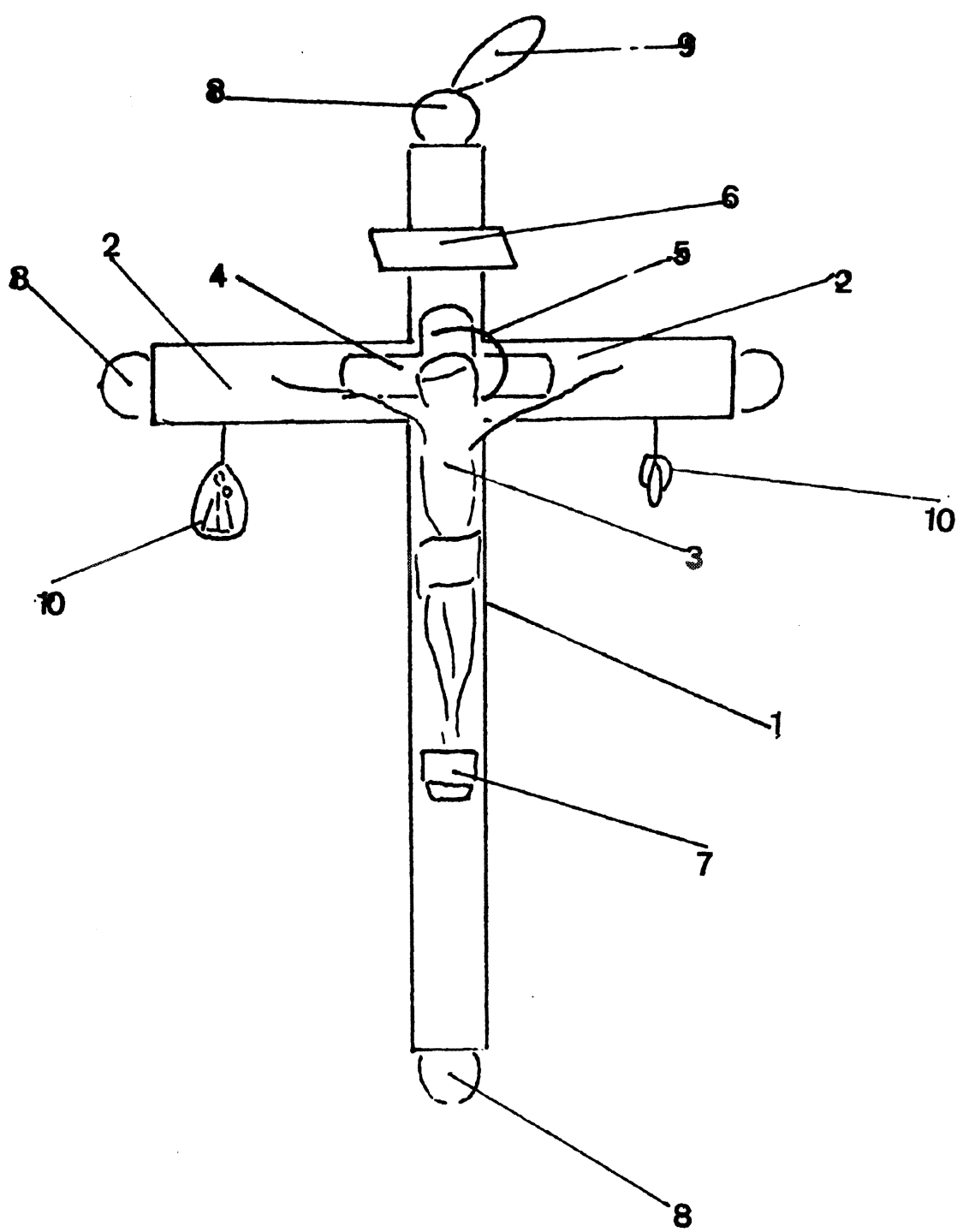

FIG. 5.-Siglo XVII. Esquema general de la cruz, elementos y nombres que recibe. 1) Palo o Cruz: Puede ser: a) embutido; b) liso; c) apanalado. 2) Lados o Brazos (embutidos, lisos, apanalados). 3) Cristo o "Echura": a) pintada; b) de bulto (lleno, vano o hueco). 4) Veriles o Alma: si la cruz es de relicario, en cuyo caso el cristo se sustituye por reliquias. 5) Aro, rodeando la cabeza del cristo (este elemento puede supeditarse a la existencia del crucifijo). 6) Letrero o Letras. 7) Peana: a) sin más; b) de concha; c) de botón. 8) Remates: a) dos en los extremos de los brazos; b) uno en la parte superior del palo o encima; c) uno en la parte inferior del palo. 9) Argolla o asa. 10) Goteras: a) de medalla; b) de higa. 
C. CRUZ DEL SANTO OFICIO.-Esta variante, distintivo propio de los ordinarios en el cargo, aparece, como es lógico, en casos muy contados. Tan solo se documenta un ejemplo en este siglo, año 1685, en el lugar de la Alberca y testamento del clérigo D. Antonio de Velasco: "Una Cruz de oro que tengo esmaltada con la encomienda del Santo Oficion. (AHPS-P 6143, f.54).

En este siglo las cruces van formando parte como extremos de: hilo de gabanzas, vuelta, sartal, rosario, vidrieras o relicarios.

Sobre las fechas o fiestas señaladas en que es costumbre regalar cruces y la clase social que utiliza esta pieza como regalo, sabemos que en San Martín del Castañar en el año 1633 se regaló en unas Vistas, entre otras cosas, "un cristo de plata dorado" (AHPS-P 6188, f.194v).

En 1671 el licenciado Jacinto de Párraga, presbítero y hermano del alcalde mayor de San Martín por el estado noble, deja en testamento a su hermana "una cruz de oro" (AHPS-P 6189, f.95).

Asímismo, en el Inventario de alhajas de N. ${ }^{a}$ S. ${ }^{a}$ del Rosario de Miranda (APM Inv. de 1637, s.f.), figura entre otras joyas "una cruz, la de Jerónimo de Moreruelan, como donación de este noble mirandeño.

\section{EL SIGLO XVIII}

\section{Las cruces}

El esplendor que caracteriza las cruces en el siglo XVIII en la Serranía de Francia y Candelario por la abundancia y variedad de formas y labores se muestra en un total de 204 documentos entre los que destacan los 74 de Cepeda.

LUGARES, CANTIDAD Y AÑO PRIMERO Y ÚLTIMO QUE SE REGISTRAN:

\begin{tabular}{|l|c|c|}
\hline \multicolumn{1}{|c|}{ LOCALIDAD } & PIEZAS & AÑOS \\
\hline Cepeda & 74 & 1701,1798 \\
Candelario & 48 & 1713,1799 \\
Alberca & 29 & 1727,1793 \\
Miranda & 18 & 1715,1799 \\
Sequeros & 13 & 1704 \\
Villanueva & 8 & 1782,1796 \\
San Martín & 7 & 1704,1799 \\
Casas del Conde & 3 & 1782,1789 \\
Sotoserrano & 3 & 1790,1797 \\
Monforte & 1 & 1782 \\
\hline
\end{tabular}




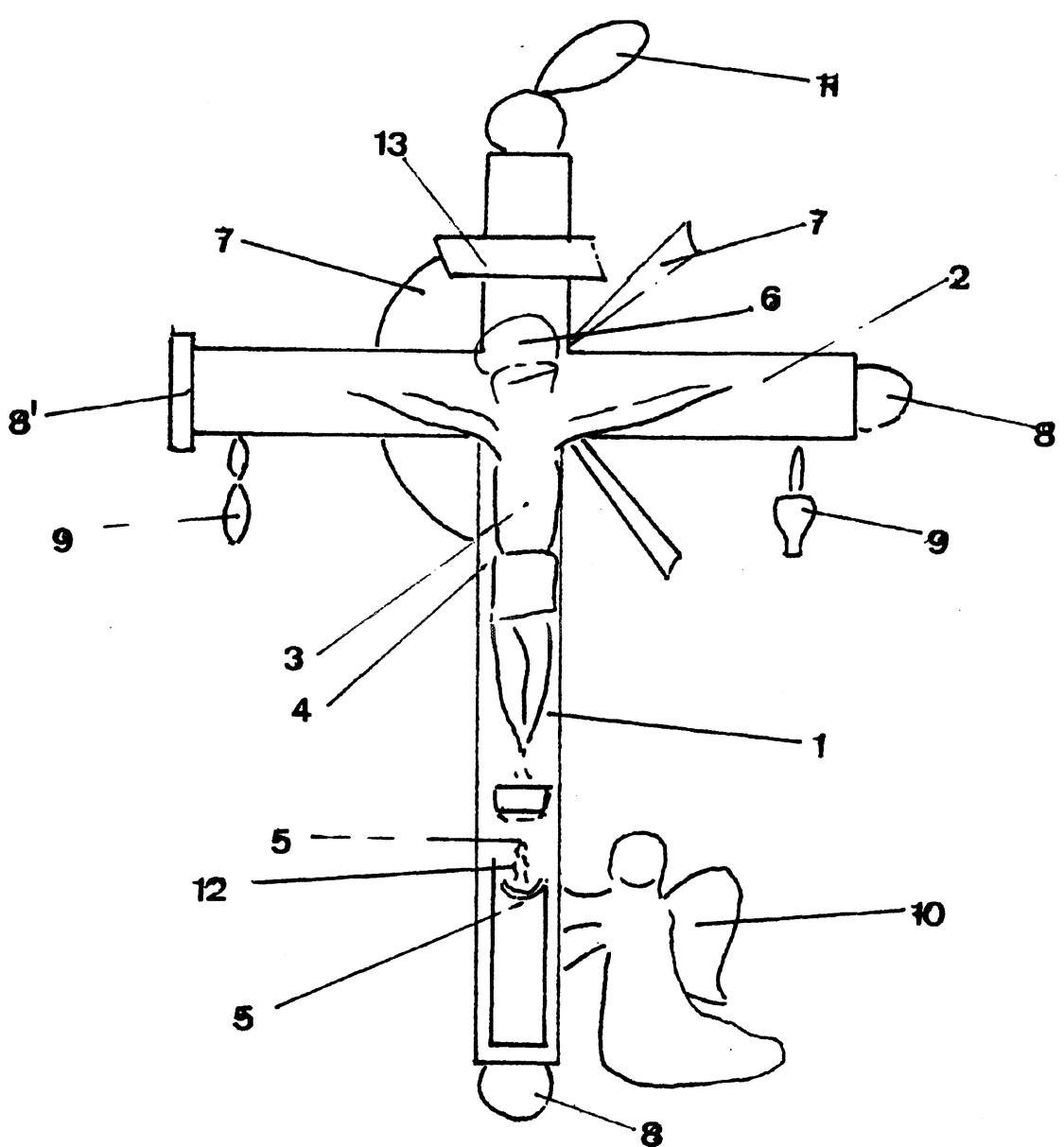

FIG. 6.-Siglo XviII. Esquema de la cruz, elementos y nombres que recibe. 1) Palo o cruz. 2) Lados o brazos (el 1 y el 2 pueden ser: embutidos, lisos, con alma, apanalados, de "echura de Portugaln, calados, afiligranados, guarnecidos de perlas). 3) Cristo o echura de bulto (va en la parte de la cruz denominada medio o enmedio). 4) Medio o enmedio. 5) Embutidero de reliquias, ánima o bueco (viriles en el s. XVII). Las reliquias en el ánima van sustituyendo al cristo; suelen llevar como protección las vidrieras. 6) Corona (aro en el s. XVII). Generalmente es redonda y ocupa la parte del medio, con o sin cristo. 7) Cerco, cerquillo, flechas y estrellas. 8) Estremos o remates: de botón, de engaste a martillo, de gastones sin más. 9) Pendientes (goteras en el s. XVII). Pueden ser pendientes sin más, almendrillas, palomas, jarritas, almenas o almenillas. 10) Serafines o ángeles (se dan siempre en la cruz de Oviedo y a veces en la de Caravaca). 11) Asas o cadena y lazo. 12) Imáxenes: N. S. $^{a}$ o Concepción, cabeza de serafín, calvario, calavera (unas figuras van al dorso de la cruz y otras bajo la peana). 13) Letrero. No hay en este siglo referencia documental pero es obvio que se da, y se confirma con la joya-testigo. 


\section{ELEMENTOS DE LA CRUZ QUE APARECEN DOCUMENTADOS EN ESTE SIGLO:}

Brazos: En la descripción de la cruz suele omitirse el palo, que se divide en cimero y bajero, enumerándose tan solo los brazos de los que cuelgan los pendientes. Los brazos y palo pueden ser:

- Macizos o llenos (no hay ejemplos explícitos).

- Huecos o de ánima: En ocasiones y cuando la cruz no lleva crucifijo se presenta ahuecada, toda o en parte, con un ánima de vidrieras o viriles para embutir en ellos reliquias. En Cepeda en 1708 se citan “dos crucitas de madera, la una con guecos de reliquias" (AHPS-P 5998, ff.6265v). En la misma localidad y año se describe otra "cruz de madera con bidrieras" (AHPS-P 5998, f.168 y ss.). En la Alberca, año de 1776: "crucezita de ánima engastada en plata" (AHPS-P 6118, f.16v). En Candelario, 1789: "cruzita de ánima" (AHPS-P 1142, f.67). En Cepeda, 1794: "cruz de ánima perteneciente a corona ${ }^{12}$ (AHPS-P 6016, f.79). En Miranda, 1719: “cruz embutida de reliquias" (APM Inv. Humilladero s.f.)

12 De las tres variantes principales de rosario, atendiendo al número de cuentas, fórmulas que se rezan y formas que adopta, el más conocido es el rosario dominicano (simpificado o de cinco dieces, y completo o de quince misterios: gozosos, dolorosos y gloriosos), rosario por antonomasia o sin más. En segundo lugar, la camándula o camáldula, de uno o tres decenarios, la variante quizá, mejor representada en la iconografía de los siglos XV y XVI. Por último, la corona: rosario de siete misterios que contempla los Dolores de María. En las joyas-testigo que han llegado hasta nosotros predominan en su material las cuentas negras - azabache y madera- y se emplea como joya de luto. Ver en A. CEA GuTIÉRREZ, "Los ciclos de la vida: ritos y costumbres en torno a los difuntos ...”, RDTP, XI (1985), pp. 21-68, especialmente la lám. IV, 2 y la fig. 4. De los 50 ejemplos de rosario, documentados en estas comarcas en el siglo XVII, sólo dos son coronas. Una en Cepeda, año 1642: "rosario de cristal de sesenta y ocho piezas de cristal en un listón azul quinze reales" (AHPS-P 5981, f.188). No tenía padrenuestros y faltaban dos avemarías. La otra en Sequeros, año 1698: aun rosario de coral, tiene los paternostes dorados, ochenta y cuatro corales y seis paternostes y una encomienda de oro del Santísimo Cristo, esmaltadon (AHPS-P 6234, f.260). En el siglo XviII, época de esplendor aquí de los rosarios, según se desprende de la documentación con 284 ejemplos, 27 de ellos refieren a coronas. Se incorpora además la variante conocida como "Corona de Jerusalén" en 66 ocasiones entre los años 1754 y 1799 (Candelario a la cabeza con trece ejemplos y la Alberca con ocho). En este período la voz corona parece emplearse indistintamente con la de rosario. En San Martín del Castañar se cita en 1793 "una coronilla dominica", sinónimo sin duda del rosario de cinco dieces (AHPS-P 6207, f.17 y ss.). En el siglo XIX se registra 106 veces la voz rosario y 32 la de corona (mantiene Candelario los 13 ejemplos y se incrementan en la Alberca a 9). En Cepeda, entre 1806 y 1823, cuatro coronas llevaban por remate cruces de Santo Toribio y dos el Cristo de Burgos. En San Martín en el año 1845 (APSMtn, f.2) se menciona, entre otras alhajas parroquiales, "una corona de monjas blanca con una medalla de plata", joya que no debemos aceptar como una variante temática, sino como ahechura de monjas» y fenónemo paralelo al de los 
Pendientes: Los pendientes, que adoptan diversas formas sin especificar, van colocados bien en número de dos - uno en cada brazo- o en los cuatro cabos o extremos. En ocasiones se presenta solo un pendiente en el remate del palo bajero o del cimero: "cruz de oro y su pendiente al remate de la cruz 96 rs". Alberca, 1732 (AHPS-P 6103, f.139). "Cfjo pequeño con tres pendientes". Alberca, 1754 (AHPS-P 6111, f.30v). "Cristo con unos pendientes". San Martín, 1704 (AHPS-P 6195, f.34v y ss.).

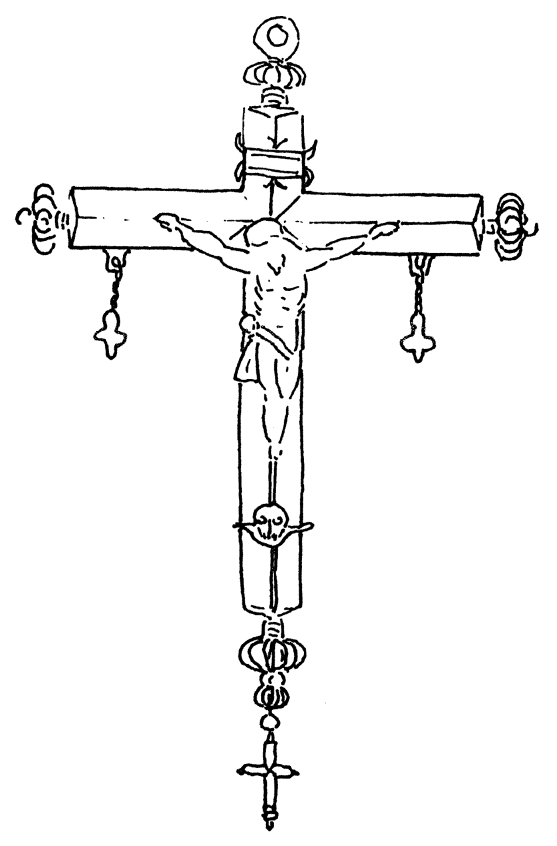

Fig. 7.-Cruz de plata seca con brazos y palo apanalados y hechura del cristo de bulto lleno. Letrero y calavera. Los remates del palo -cimero y bajero-y los brazos, en labor de filigrana. Los pendientes de los brazos en paloma, el del palo en crucita. Asa redonda. Aunque los pendientes de paloma no aparecen en documentos anteriores a 1769 , pudieron darse primero. La cruz no tiene aún cerco ni rayos, elementos muy al gusto de la segunda mitad del xviII. Fecharíamos esta pieza a caballo entre los siglos xvil y xviII. Pertenece a la vuelta grande de las Vistas (La Alberca, col. de los Hoyos Puerto).

corazones y escapularios, generalmente de seda y guarnición bordada. Sí conserva la Alberca una curiosa variante, quizá de la de Jerusalén, conocida como "la corona del Peregrino", fórmula traída como novedad por un hijo del pueblo a la vuelta de Tierra Santa y que quedó incorporada a la devoción popular albercana hasta hoy. Formalmente la corona consta de cuatro elementos: Las avesmarias o decenarios, también denominados cuentas, contaderas, avellanas, lágrimas, y, más genéricamente, sartas. En segundo lugar, los paternostes o entrecuentas, casi siempre de mayor tamaño que las avesmarías que separan, distinto material y formas lisas o labradas de filigrana, estrelladas, a manera de gabanzas, avellanas, jesuses, cruces, etc. Como extremos y en tercer lugar: cruz o cruces, relicarios, medallas, veneras y encomiendas, copetones o perillas de seda. Por último, el engarce de todo lo anterior, de metal (alambre, alquimia, plata, oro), de listón de seda o de cordón o cañoncitos. El material predominante de la corona es el azabache y después el coral, luego diversas calidades de piedras entre las que no falta la venturina, nácar, perlas, hueso, ámbar, madera y otros. Las labores lisas o afiligranadas, estrelladas, confitadas, de bueso de aceituna y de bueso de santo, de cocos, de frutilla, de remos o remas, etc. 
- Jarritas: "cristo de plata con sus jarritas pendientes". Cepeda, 1704 (AHPS-P 5997, ff.336-337).

- Almendrillas: "cruz de diamantes y troqueles con tres almendroncitos y votón arriva". Monforte, 1749 (APM Inv. de la Cuesta s.f.). "cruz con sus almendrillas de plata aumada". Cepeda, 1764 (AHPS-P 6008, ff.212 y ss.). "con tres almendrillas grandes aumadon. Cepeda, 1764 (AHPS-P 6017, f.187 y ss.). "Cristo mediano con almendrillas". Monforte, 1782 (AHPS-P 6181, f.14).

- Palomas: "cristo con una palomita". Cepeda 1769 (AHPS-P 6009 f.28 y ss.).

- Almenas: “Cristo grande de plata con unas almenillas". Alberca, 1782 (AHPS-P 6120, f.116v).

Extremos o Remates: "cruz de madera embutida de reliquias y estremos de plata de martillon. Miranda, 1719 (APM Inv. Humilladero de 1637 s.f.). "cruz con los estremos de plata.. San Martín, 1749 (AHPS-P 6203, f.71v). "cruz de palo con estremos y cadena de plata". San Martín, 1775 (AHPS-P 6118, f.80). "cruz de palo con estremos de plata". San Martín, 1776 (AHPS-P 6118, f.16v).

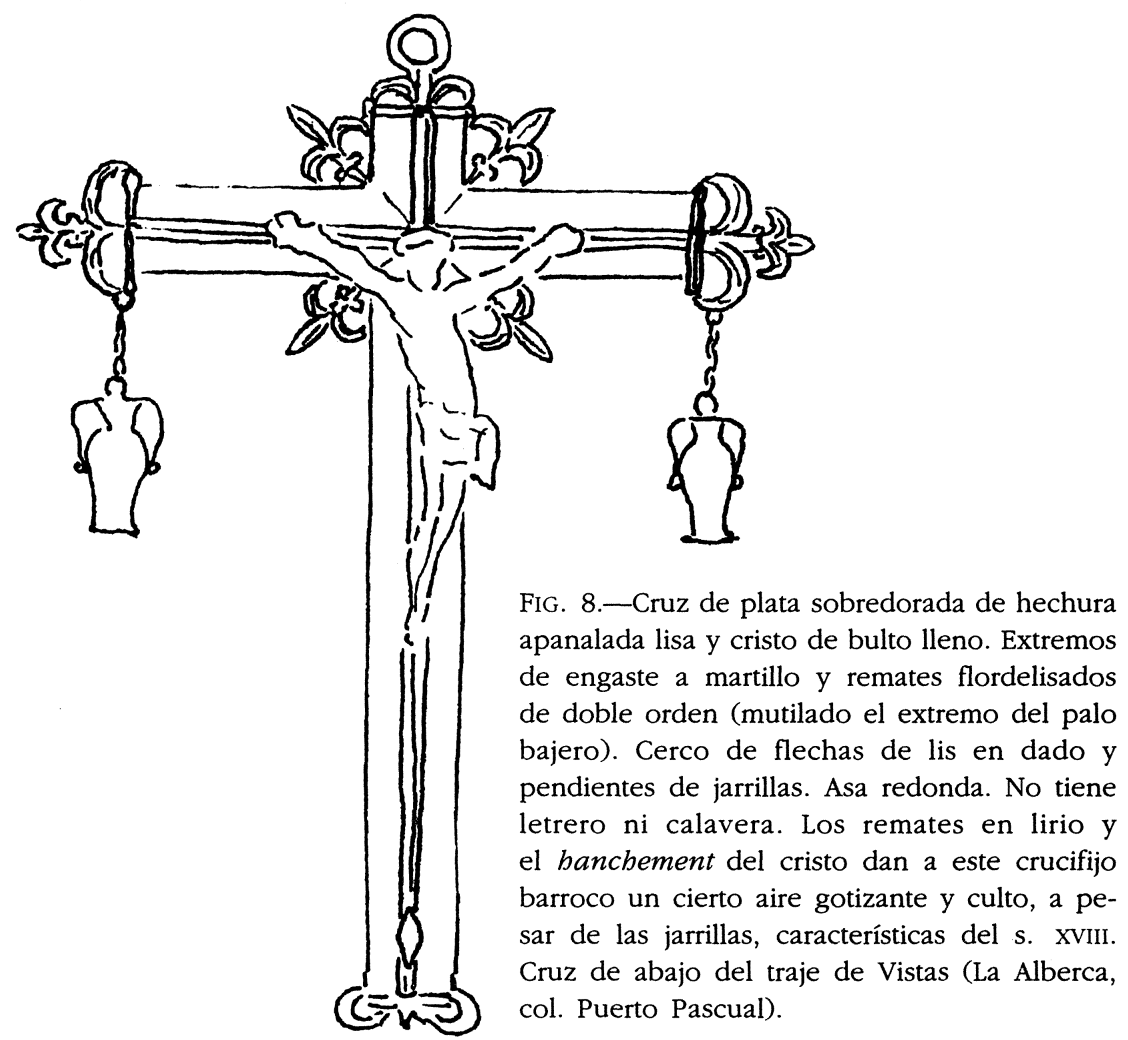


Medio o "Enmedio". Se llama medio o enmedio a la parte central que suele ocupar el cristo: "cruz de piedras verdes salvo el medio que es azul". Candelario, 1781 (AHPS-P 1140, f.27).

Cristo: Cuando la cruz lleva cristo, este va en el anverso o cara y en el reverso o espalda, acaparándola, una hechura advocacional generalmente de la Virgen -hay alguna pieza-testigo de Pilara-, y bajo la peana puede llevar una Concepción de medialuna. Los cristos se describen como de bulto, pero no se especifica si la labor es de bulto lleno o bulto hueco: «echura de Cristo de bulto y una verónica». Cepeda, 1706 (AHPS-P 5998, ff.140-141).

Cerco o Flechas (aro en el siglo xvII). De los ángulos del palo y brazos nace un elemento llamado cerco si su forma es circular, flechas o rayos si es radial y dado si es cuadrado. Los rayos suelen variar de número, entre uno y seis a cada lado: "cruz con cerco de plata a modo de los zercos en que se engastona la ymagen de Santa Teresan. Sequeros, 1705 (AHPS-P 6237, f.112).

Asas: Las asas constituyen el punto de unión entre la cruz y la cadena o argolla: "crucita pequeña sin asas". Cepeda, 1705 (AHPS-P 5997, ff.287-288v).

Serafines o Ángeles: Es este un elemento de la iconografía de Caravaca y Oviedo que puede a veces contagiar otras cruces. Los ángeles van arrodillados y tenantes. En los documentos en que se describen tres, uno de ellos se sitúa bajo la peana y suele ser en "echura" de cabeza de serafín: "cruz de madera engastonada de plata con tres serafines". Alberca, 1733 (AHPS-P 6103, f.81v y ss.). "cruz de plata que la tienen dos ángeles". Alberca, 1776 (AHPS-P 6011, f.81 y ss.).

Listón o Cinta: Cuando la cruz no va formando parte como extremo de hilo o vuelta sino sola "al pescuezo", suele ir prendida de un cordón o listoncillo, predominantemente en colores negro o "colorado"; "cruzita afeligranada con un listón colorado. San Martín, 1725 (AHPS-P 6199, f.102v); "cruz vieja con su cinta tres rs". Villanueva, 1789 (AHPS-P 6326, f.7); "cruz de piedras y plata aumada con cinta negra para el pescuezo". Cepeda, 1762 (AHPS-P 6007, f.137); "cruzita con piedras verdes 4 reales y no tiene listón". Candelario, 1762 (AHPS-P 1138, f.8 y ss.); "cruzita con su listón. . Candelario, 1768 (AHPS-P 1138, f.13). «[...] con piedras verdes corona y listón 8". Candelario, 1769 (AHPS-P 1138, fol. suelto). "cruzita de lazo con listoncillo negro $11 \mathrm{rs}$. Candelario, 1781 (AHPS-P 1140, fol. suelto); "cruz con cinta de terciopelo para el cuello doze. Candelario, 1787 (AHPS-P 1141, f.44 y ss.); "cruz pequeña de las de lazo sin listón seis". Candelario, 1789 (AHPS-P 1142, f.17 y ss.).

Lazo: No debemos confundir la voz lazo con las de listón o cinta. El lazo es en este caso el elemento de orfebrería cimero de la cruz que si- 
gue el esquema de la arracada de tipo cortesano, compuesta por tres órdenes: botón, lazo y pendiente propiamente dicho. Aunque los ejemplos documentales que hablan de este elemento no aluden a material alguno del que se compone, se sobrentiende que es el mismo que el resto de la cruz. A partir del último decenio del siglo prolifera esta modalidad de cruz de lazo en Candelario, corriente que no contamina a la serranía de Francia: "cruz de lazo". Candelario, 1790, 1794, 1795, y 1796 (AHPS-P 1142, 15 ff. y f.9v; f.39 y f.51 y ss.).

Cadena: "cruz de estremos y cadena de plata". San Martín, 1742 (AHPS-P 6203, f.171v). "cruz de palo con estremo y cadena de plata". Alberca, 1775 (AHPS-P 6118, f.80)

Botón: Repitiendo en este elemento lo que dijimos para el lazo, señalamos el botón como uno de los órdenes que se establecen en el remate cimero del palo coronando la cruz. Aparece este elemento por vez primera en un texto de Miranda del año 1749: "Cruz de diamantes y troqueles [...] y votón arriva y votón por coronaw. Se trata de una joya perteneciente a la imagen de Santa María de la Cuesta (APM Inv. Cuesta de 1637 s.f.). Los otros tres ejemplos corresponden a Candelario, pasada ya la mitad del siglo. Año 1769: "cruzita de botón 7 rs" (AHPS-P 1139, fol. suelto). Año 1765: "cruz de botón de plata" (AHPS-P 1135, f.52 y ss.). Año 1795: "cruz de lazo con botón para el cuello" (AHPS-P 1142, f.35).

LABORES QUE ADORNAN LA CRUZ:

Filigrana: "cruz feligranada de oro". Sequeros, 1733 (AHPS-P 6240, f.65v). "cruz afeligranada". San Martín, 1725 (AHPS-P 6199, f.102v).

¿Echura de Portugalv: En Miranda del Castañar, año 1771, se dice en el inventario de la Cuesta: "el reverendo Padre Francisco de la Peña natural desta villa, religioso profeso de la Orden de N. ${ }^{a}$ S. ${ }^{a}$ de la Merced Calzada, me entregó una chruzita de oro de echura de Portugal y dixo la daba de limosnaw. Parece referirse a una determinada variante de cruz propia de Portugal, aunque no descartamos que aluda solo a la calidad del material (APM Inv. Cuesta, 23-X-1771, s.f.).

Hueca o con alma: "la una cruz con guecos de reliquias" (con embutideras). Cepeda, 1708 (AHPS-P 5998, f.62-65v).

Guarnecida: "cruz de feligrana de oro y guarnición de perlas". Sequeros, 1733 (AHPS-P 6240, f.65v).

Engastonada: "cruz engastada en plata". Alberca, 1733 (AHPS-P 6103, f.81v y ss.). "cruzecita de ánima engastada en plata". Alberca, 1776 (AHPSP 6118, f.16v).

Teñida: "Cristo de bronze en cruz de madera teñida de negro". Sequeros, 1748 (AHPS-P 6224, f.21v). 


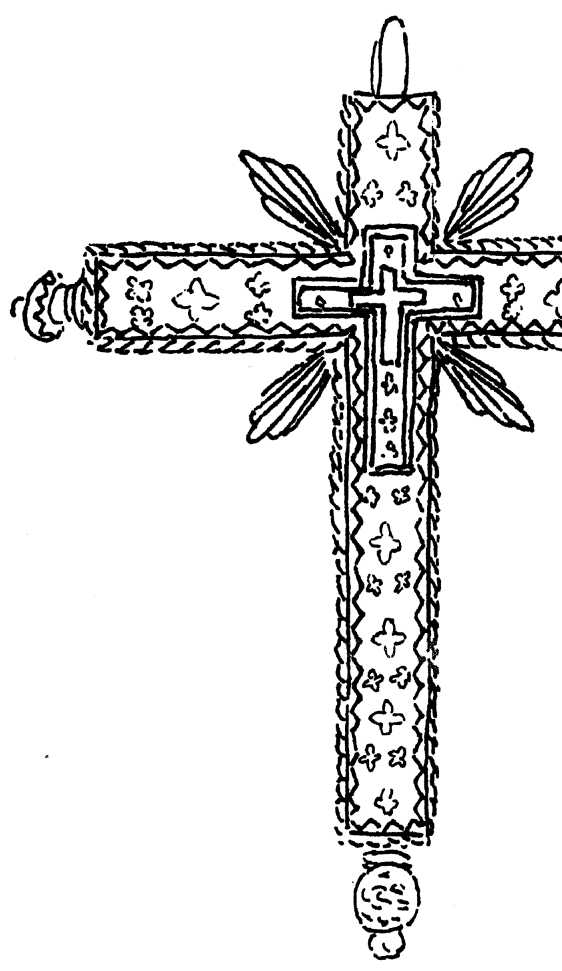

FIG. 9.-Cruz de rosario de plata y nácar. Palo y brazos, embutidos de labores de taracea de nácar con motivos de crucitas treboladas. El enmedio doblemente encrucetado a taracea, simulando un embutido de reliquias y lignum central. Toda la cruz va cercada por una armación dentada de plata y cordoncillo de lo mismo. Extremos de botoncillo calado. Cerco con rayos romos de a cinco, de plata lisa. Asa perpendicular. Últimos años del siglo xviII o primeros del XIX (La Alberca, col. de los Hoyos Puerto).

TAMAÑOS DE LA CRUZ:

\begin{tabular}{|l|c|l|l|}
\hline \multicolumn{1}{|c|}{ TAMAÑOS } & PIEZAS & \multicolumn{1}{|c|}{ LOCALIDAD } & \multicolumn{1}{c|}{ AÑOS } \\
\hline pequeña & 17 & Cepeda & 1704,1740 \\
pequeña & 3 & Miranda & 1727,1755 \\
pequeña & 5 & Alberca & 1734,1776 \\
pequeña & 1 & Sequeros & 1749 \\
pequeña & 15 & Candelario & 1769,1796 \\
grande & 1 & Miranda & 1749 \\
grande & 3 & Alberca & 1744,1758 \\
grande & 1 & Cepeda & 1798 \\
gruesa & 1 & Miranda & 1772 \\
\hline
\end{tabular}

UBICACIÓN DE LAS CRUCES EN EL CUERPO:

De gargantilla: La garganta es la parte más alta del cuerpo en que puede ir colocada una cruz, y la gargantilla suele ser de un solo hilo: "Cruz de gargantilla de plata". Villanueva, 1790 (AHPS-P 6236, f.82). "dos cruzes de gargantilla viejas". Villanueva, 1793 (AHPS-P 6328, f.148). 


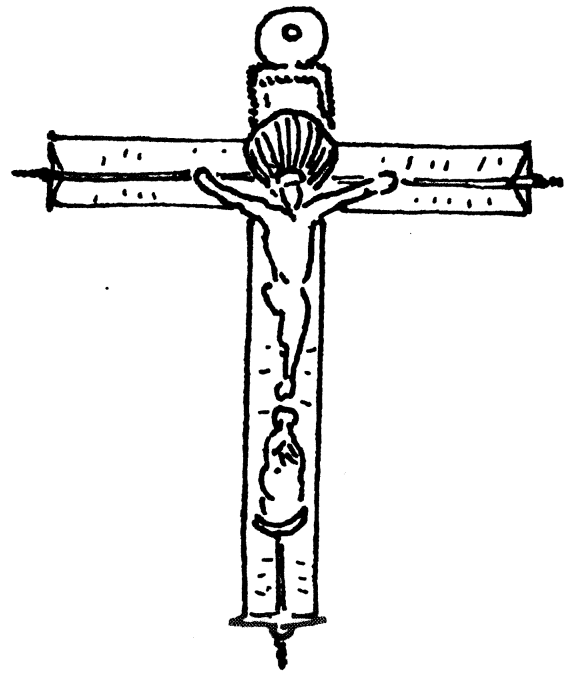

FIG. 10.-Cruz de oro que sirve como extremo de hilo "de atar al pescuezo". Hechura apanalada con labores de rombos a buril y remates de granos o pezuelos. En el enmedio, cristo de bulto hueco y Concepción de media hechura hueca como peana. Aro o corona aconchada a manera de dosel. Asa de lámina redonda. Quizá sea este crucifijo de los calificados en los documentos de 1771 como "de echura de Portugal" (Miranda, col. Juan Coca González).

De cuello o pescuezo: "cruz con cinta negra para el pescuezo". Cepeda, 1762 (AHPS-P 6007, s.f.).

Candelario nos ofrece 26 ejemplos de cruces para prender del cuello entre los que destacamos el siguiente: "cruzita de lazo de las de adorno al cuello 10 rs". 1779 (AHPS-P 1140, f.6 y ss.). Según estas descripciones candelarias, la cruz solía colgarse de un listón y era de las denominadas "de lazo y botón", llevando casi siempre como guarnición una piedra o piedras verdes (AHPS-P 1139-1140-1141-1142-1143). En la Alberca en 1776 se registra una "cruz del cuello", de plata de Córdova doze rs". (AHPS-P 6118, s.f.). En Sequeros año 1771: "cruz del cuello de plata" (AHPS-P 6250, f.65) y en 1779 "Cruz de plata del uso de las mujeres a el cuello doze rs" (AHPS-P 6252, f.135 y ss.).

En la zona del cuello o "pescuezo" entran varios tipos de collares de diversos tamaños, desde los manojitos, en la raíz de la garganta, pasando por la zona del pecho, donde nacen y se alojan las llamadas "vueltas chicas" del traje de Vistas.

Del cuello "de las de abajo": Se entiende la zona ya a la altura del pecho sin caer a la cintura. A partir de ahí se colocan las tres vueltas grandes de las Vistas conocidas por: vuelta chica (entre las grandes), vuelta del medio y vuelta grande o de abajo propiamente dicha, que puede llegar casi hasta el ruedo del manteo o saya. En Cepeda recogemos en 1798 el documento siguiente: "cruz del pescuezo de las de abajo" (AHPS-P 6017, f.107 y ss.). 


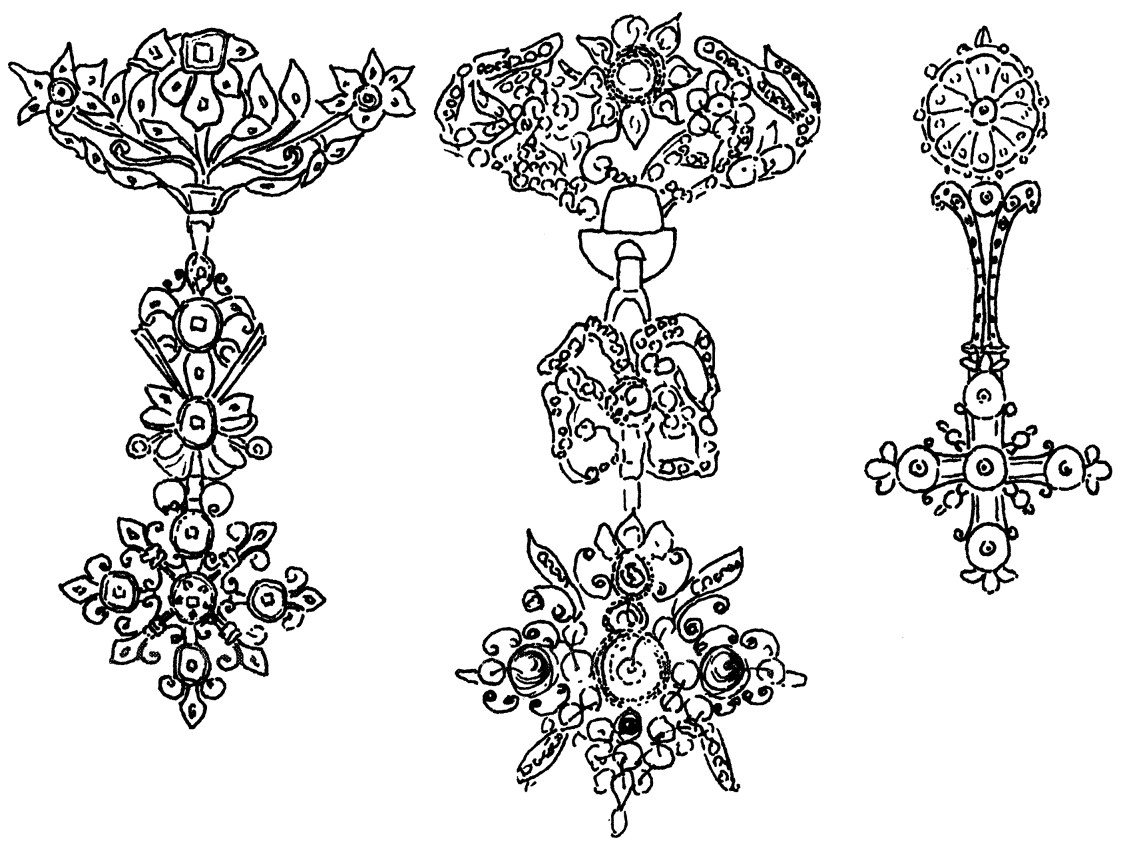

FIG. 11.-Cruces de aderezo o gargantilla. Estas joyas van siempre elaboradas con materiales preciosos: oro, piedras y aljófares y su hechura corresponde a las características de labor "erudita", propia del siglo XVIII y recogida y mantenida en el XIX por los estratos más poderosos de aldeas y villas, constituyendo, casi siempre, parte de los bienes dotales entre las familias adineradas. Aunque es probable que algunas joyas-testigo se inscriban en cánones comprendidos en la segunda mitad del siglo XIX, transmiten su forma inalterada justamente de un siglo antes, hacia mediados del XVIII. La arriería a Córdoba, Portugal y Galicia fue sin duda una fuente de importación de modelos como el que se cita en la Alberca en 1776 ade plata de Córdova" o la pieza $a$, que quizá tenga la misma procedencia. a) Cruz de oro y diamantes que forma parte como extremo de un hilo de granos calados. La labor principal es de laminillas embutidas con chispas de diamantes en forma de rosetas o, según documento mirandeño de 1797, "aderezo clabado en fino". Consta de: corona o ramo, lazo de doble botón y cruz. La corona se compone de tres ramos de laminillas muy delicadas, con rosas de a seis y en cada una, embutida, una chispita de diamante. El lazo es doble, del tipo conocido entre los plateros serranos como alazá chican. En su centro un casquillo con diamante embutido y cordoncillo. La cruz lleva cuatro cabezas con diamantes y cerco de cordoncillo. El cuadro o dado se forma por cuatro rayos flordelisados y el centro, una laminilla con chispa de diamante, sostenida por dos caramullos, igual que en los extremos de brazos y palo. ¿Último cuarto del siglo xviII? (La Alberca, col. Serrano Becerro), b) Joya de aderezo de oro y aljófares de tres órdenes: la corona está formada por ramo de tres rosas centrales y hojas alrededor. El asiento de las rosas es de torzalitos de oro afiligranado que reciben un lleno de perlas menudas berruecas, conocidas en la Sierra como "algolfan, cada una enhebrada por un macho de oro. Las hojas son piernitas lisas con cuatro o cinco aljófares como lleno o guarnición. El elemento central lo forma la lazada, que es "chican y "de mariposa", con la misma guarnición que la corona, añadiendo al lleno, sobre el azafate central, un cordoncito de aljófares, diminutos en extremo. La cruz, adornada en su cuadro por filigranas de caramullos sostenidos por azafates y en cada hollete una perla. Los rayos, piernas guarnecidas de menor tamaño. ¿Último tercio del siglo xviII? Forma el extremo de un hilo de cuentas de cascos lisos (Miranda, col. Juan Coca González). c) Cruz de diamantes de aderezo, del que se conservan también los pendientes. Creemos identificar esta pieza con la inventariada en el Libro de Cofradía de N." S. ${ }^{a}$ de la Cuesta, entre sus alhajas, en los años 1749 y 1770 , donde se describe como acruz de diamantes y troqueles con tres almendroncitos y votón arriva y un votón por corona, el Qual dio Don Pedro Prado, Alcalde mayor . En efecto, lleva por corona un botón o estrella de casco liso y granos a los extremos. Lazo en *Y, guarnecido por grecas de diamantes y cruz de cuatro cabezas que son cascos donde van, "clavados a lo fino", diamantes, tres granos haciendo los picos y almendrada en los extremos. El cuadro de la cruz lo forman cuatro rayos de caramullos (Miranda, joyero de $\mathrm{N}^{\mathrm{a}} \mathrm{S}^{\mathrm{a}}$ de la Cuesta). 
MATERIALES Y AÑOS:

\begin{tabular}{|l|l|l|}
\hline \multicolumn{1}{|c|}{ MATERIALES } & NÚM. PIEZAS/LOCALIDAD & \multicolumn{1}{|c|}{ AÑOS } \\
\hline plata & (5) Candelario & 1717,1799 \\
plata & (7) Miranda & 171,1792 \\
plata & (5) Sequeros & 1740,1779 \\
plata & (2) Villanueva & 1782,1790 \\
plata & (1) Sotoserrano & 1797 \\
plata ahumada & (1) Sequeros & 1704 \\
plata ahumada & (1) Cepeda & 1705 \\
plata "Sahumada" & (1) Candelario & 1712 \\
plata seca & (1) Candelario & 1731 \\
plata "por ahumar" & (1) Cepeda & 1705 \\
plata sobredorada & (2) Miranda & 1749,1775 \\
plata sobredorada & (1) Candelario & 1794 \\
plata sobredorada & (1) Casas del Conde & 1799 \\
oro & (3) Miranda & 1715,1771 \\
oro & (1) San Martín & 1789 \\
oro & (2) Villanueva & 1790,1796 \\
oro & (2) Sotoserrano & 1790,1797 \\
oro y porcelana azul & (1) Miranda & 1770 \\
oro y perlas & (1) Sequeros & 1733 \\
azabache & (2) Sequeros & 1701 \\
bronce y madera & (1) Sequeros & 1748 \\
bronce y piedras falsas & (1) San Martín & 1725 \\
piedras verdes & (15) Candelario & 1759,1786 \\
plata y piedras verdes & (2) Candelario & 1769,1795 \\
plata y piedras verdes & (1) Casas del Conde & 1782 \\
anacarada & (3) Candelario & 1781,1784 \\
hueso & (1) Cepeda & 1705 \\
\hline
\end{tabular}

PRECIOS QUE ALCANZAN EN ESTE SIGLO LAS CRUCES

\begin{tabular}{|c|c|c|c|}
\hline LOCALIDAD & MÁXIMO & MEDIO & MÍNIMO \\
\hline Sequeros ..................... & $112 \mathrm{rs} \mathrm{vn}$ & $14 \mathrm{rs}$ & $12 \mathrm{rs}$ \\
\hline Sotoserrano .............. & $100 \mathrm{rs}$ & - & 80 rs \\
\hline Alberca ......... & $96 \mathrm{rs}$ & $36 \mathrm{rs}$ & $10 \mathrm{rs}$ \\
\hline Villanueva & $40 \mathrm{rs}$ & $28 \mathrm{rs}$ & $3 \mathrm{rs}$ \\
\hline Candelario ............... & $32 \mathrm{rs}$ & $15 \mathrm{rs}$ & $4 \mathrm{rs}$ \\
\hline Casas del Conde. & $28 \mathrm{rs}$ & $18 \mathrm{rs}$ & $12 \mathrm{rs}$ \\
\hline 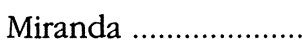 & $16 \mathrm{rs}$ & $12 \mathrm{rs}$ & 8 rs \\
\hline Cepeda & $15 \mathrm{rs}$ & $5 \mathrm{rs}$ & $2 \mathrm{rs}$ \\
\hline
\end{tabular}


PESO QUE ALCANZAN:

Dos onzas: "Crucifixo aumado grande". Alberca, 1744 (AHPS-P 6117, f.191v).

Una onza: "echura de Cristo y dos Santas de plata seis reales que pesan la onza". Candelario, 1720 (AHPS-P1134, f.20 y ss.).

Media onza: "Cristo de plata de media onza escasa". Cepeda, 1704 (AHPS-P 5997, ff.212-215v).

CANTIDAD MÁXIMA DE CRUCES POR PERSONA:

Alberca y Candelario tres cruces; Casas del Conde, Cepeda, Miranda, San Martín y Villanueva dos cruces respectivamente.

Las cruces se empleaban como regalo o dádivas entre novios en Candelario, como consta en un texto de 1799: "de dádivas para el día del Corpus" (AHPS-P 1143, f.18). También como regalo dotal en otros tres ejemplos de Casas del Conde.

En este siglo las cruces sirven como extremo a las alhajas siguientes:

\begin{tabular}{|l|r|l|}
\hline \multicolumn{1}{|c|}{ ALHAJA } & PIEZA & \multicolumn{1}{|c|}{ LOCALIDAD } \\
\hline argolla & 20 & Cepeda \\
hilos sin especificar & 17 & Cepeda \\
hilos sin especificar & 1 & Sotoserrano \\
hilos de coral & 9 & Cepeda \\
hilos de sartas & 2 & Cepeda \\
sartal de avellanas & 1 & Candelario \\
hilo de plata & 1 & Cepeda \\
vueltas de coral & 3 & Cepeda \\
manojitos de coral & 1 & Alberca \\
vuelta de gabanzas & 2 & Alberca \\
rosario & 1 & Candelario \\
corona & 1 & Cepeda \\
barquillo o vaso & 1 & Cepeda \\
\hline
\end{tabular}

2. ADVOCACIONES DE LAS CRUCES EN ESTE SIGLO

A. CARAVACA.

LUGARES, CANTIDAD Y AÑOS PRIMERO Y ÚLTIMO EN QUE SE DOCUMENTA:

\begin{tabular}{|c|c|c|}
\hline LOCALIDAD & PIEZAS & AÑOS \\
\hline Cepeda ......... & 12 & 1701,1798 \\
\hline San Martín & 6 & 1704, 1782 \\
\hline Sequeros .... & 5 & 1704,1753 \\
\hline Alberca ................ & 4 & 1729,1779 \\
\hline Miranda ................. & 2 & 1771,1783 \\
\hline Candelario .......... & 1 & 1768 \\
\hline Villanueva ........ & 1 & 1778 \\
\hline Sotoserrano $\ldots \ldots \ldots \ldots \ldots \ldots \ldots \ldots \ldots \ldots \ldots \ldots$ & 1 & 1794 \\
\hline
\end{tabular}


MATERIAL DE QUE SE COMPONE:

\begin{tabular}{|l|c|l|l|}
\hline \multicolumn{1}{|c|}{ MATERIAL } & PIEZAS & \multicolumn{1}{|c|}{ LOCALIDAD } & \multicolumn{1}{|c|}{ AÑOS } \\
\hline plata & 3 & San Martín & $1704,6,82$ \\
plata & 3 & Cepeda & $1704,23,62$ \\
plata & 2 & Alberca & 1729 \\
plata & 2 & Miranda & 1771,1783 \\
plata & 1 & Villanueva & 1778 \\
"metal" & 1 & Cepeda & 1701 \\
"metal pajizo" & 1 & San Martín & 1789 \\
hierro & 1 & Cepeda & 1701 \\
madera & 1 & Candelario & 1738 \\
\hline
\end{tabular}

PRECIOS:

Miranda, 25 reales la pieza de plata; Candelario 22 rs y medio; Cepeda 2 reales (metal).

PESO:

Una libra: "Caravaca con sus ángeles de metal pajizo, pesó una livra". San Martín, 1789 (AHPS-P 6209, f.57).

Un cuarto en Candelario, 1768 (AHPS-P 1139, fol. suelto).

ELEMENTOS DE QUE CONSTA:

"Imáxenes": "Alcaravaca de plata con imaxen de Cruzifixo y nuestra señora". San Martín, 1725 (AHPS-P 6199, ff.123-125). "Alcaravaca con Cristito". Cepeda, 1745 (AHPS-P 6004, ff.52-57v).

Estrellas: La representación del sol, luna y estrellas va siempre en los brazos: "Caravaca de madera con estrellas en un quarto 22 reales y medio". Candelario, 1768 (AHPS-P 1139 s.f.).

No hemos hallado ninguna joya-testigo con representaciones.

Ángeles: "Caravaca con sus ángeles de metal pajizo pesa una livra". San Martín, 1789 (AHPS-P 6209, ff.57y ss.).

Cadena: "alcaravaca con su cadena". Alberca, 1729 (AHPS-P 6102, f.117).

No se describe otra labor en la cruz de Caravaca que la de engaste: "Caravaca engastada en plata". Alberca, 1762 (AHPS-P 6115, f.14v).

CANTIDAD MÁXIMA DE CRUCES POR PERSONA Y TAMAÑOS:

Dos cruces por persona en San Martín y Sequeros respectivamente. El calificativo de grande aparece en dos documentos: Cepeda, año 1723 y Villanueva, 1778. 
La cruz de Caravaca aparece tres veces en Cepeda formando parte de hilo y en Miranda una como extremo de dijero. En los demás documentos no se encuentra como dependiente de gargantilla, vuelta o brazalera, sí como pieza aislada.

VOCES CON QUE SE REPRESENTA:

a) Alcarabaca:

\begin{tabular}{|c|c|c|}
\hline LOCALIDAD & PIEZAS & $A \tilde{N} O S$ \\
\hline San Martín . & 3 & 1704,1725 \\
\hline Cepeda ................. & 5 & 1704,1762 \\
\hline Candelario .......... & 1 & 1768 \\
\hline Miranda ............... & 1 & 1771 \\
\hline 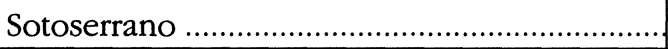 & 1 & 1796 \\
\hline
\end{tabular}

b) Carabaca: en todos los demás ejemplos

B. CRUZ DE SANTO TORIBIO.

LUGARES Y AÑOS PRIMERO Y ÚLTIMO EN QUE SE REGISTRA:

\begin{tabular}{|c|c|c|}
\hline LOCALIDAD & PIEZAS & $A \tilde{N} O S$ \\
\hline Sequeros... & 4 & 1700,1720 \\
\hline Cepeda ......... & 10 & 1701,1748 \\
\hline Sotoserrano ......... & 1 & 1708 \\
\hline Villanueva & 1 & 1778 \\
\hline
\end{tabular}

Sólo un documento de Cepeda alude al material de que se compone: "una cruz de palo" en 1719 (AHPS-P 6903, ff.10-11).

Cepeda nos proporciona el único dato que en esta centuria poseemos sobre el tamaño de la cruz de santo Toribio: "una cruzita pequeña de Liévana". 1704 (AHPS-P 5997, ff.173-177).

Asímismo, en Cepeda llega a dos el número de cruces que posee una sola persona.

LABORES:

Por el tipo de labor, engastonado o de gastones, debía ser esta cruz de las denominadas llenas o macizas. Recogemos cuatro ejemplos, el más interesante en Sequeros, correspondiente al año 1702, donde se cita una "cruz de Santo Toribio con tres encastones de plata", relativos a los brazos y palo bajero. En los otros dos documentos de Cepeda, años 1706 y 1715 y en el de Villanueva de 1778 , no se enumeran los gastones ni su material. 
Salvo en documento de Cepeda en 1700 y en otro de Sequeros de ese mismo año donde la cruz se escribe "de Santo Toribio", en los demás aparece como "santo Torivio".
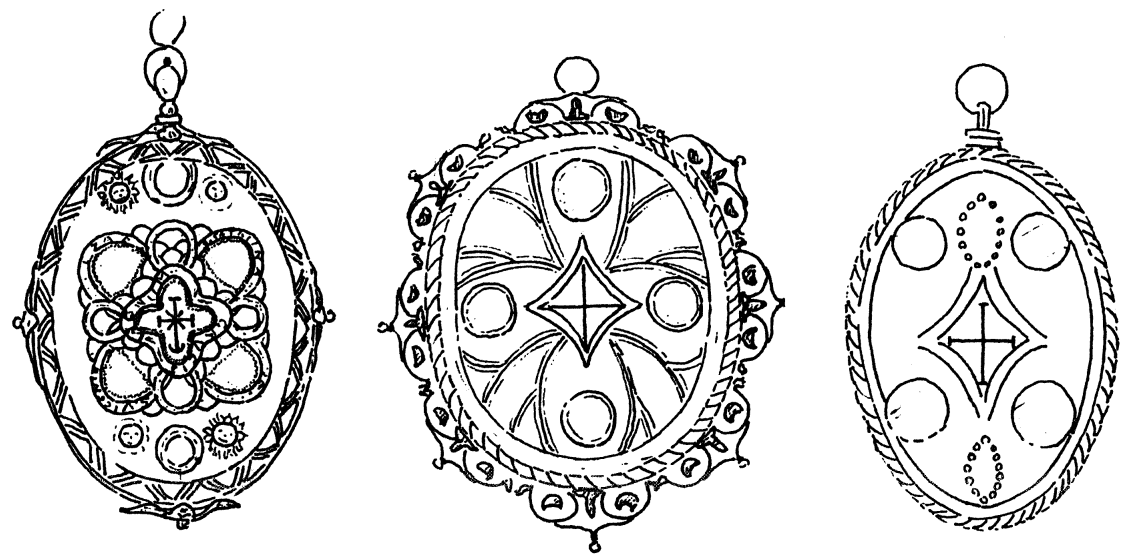

FIG. 12.-Relicarios lignumcrucis: a) Lignum de plata de dos vidrieras. La que se presenta lleva el lignum en el centro y cuatro reliquias en los ángulos de la cruz; en los extremos recortados, el sol, la luna y la tierra en medio. La caja, ovalada, es de aro de plata blanca con labores martilladas en zig-zag y cuatro granos o pezuelos haciendo la cruz. Asa de reloj. Forma parte de brazalera. Siglo Xvil (la Alberca, col. de los Hoyos Puerto). b) Lignumcrucis de plata sobredorada de dos vidrieras, en la que aparece en la figura, lignum central y cuatro tondos haciendo la cruz, donde van embutidas reliquias. La caja, atortada, de ventana lisa y cordoncillo cercando. En los extremos, haciendo la cruz y los rayos, guarnición recortada de espolones. Asa redonda. Pertenece a brazalera. Siglo XVII (la Alberca, col. de los Hoyos Puerto). c) Lignumcrucis de vidrieras con caja ovalada, ventana de aro y cerco acordonado. Asa lisa y redonda. En la vidriera de la figura, lignum central y cuatro embutideras como haciendo el tetramorfos; la guarnición, unas a modo de mandorlillas con ajolfarcitos. Pertenece a brazalera. ¿Siglo XVIII? (La Alberca, col. de los Hoyos Puerto).

\section{EL LIGNUMCRUCIS.}

No sabemos si a la denominación de lignumcrucis debiera responder también la cruz de Santo Toribio, que representa y tiene en su ánima el mayor trozo de la cruz de Cristo o Veracruz, de donde le viene el nombre a la reliquia lebaniega, o, por el contrario, debemos entender por lignumcrucis cualquier cruz en relicario con un trocito del leño santo $\mathrm{u}$ otras reliquias o imágenes. En realidad, no se puede hablar de cruz en sentido estricto, sino de un relicario, generalmente de tipo redondo u ovalado, con cerco y elementos de guarnición de diversa factura y técnica que contiene en el centro una silueta de astillas en cruz con reliquias y la leyenda LIGNUM / CRUCIS. Guarneciendo esta reliquia central suelen 
acompañar otras cuatro a los lados, bien en disposición de cruz, bien de dado o cuadro, como simbolizando los cuatro evangelios. Incluso en algún ejemplar aparecen también el sol, la luna y la tierra entre ambos.

Hemos podido recoger tres bellos ejemplares de joya-testigo de lignumcrucis, además de los 29 documentos que nos la describen.

Incluimos el lignum dentro de las advocaciones de la cruz como una variante más, porque, en efecto, se trata de una reliquia del santo leño, si bien por el respeto y la veneración que merece, los plateros dieron en guarnecerla y enmascararla con cercos y almenas, adquiriendo figura de relicario.

MATERIAL DE QUE SE COMPONE:

\begin{tabular}{|l|c|l|l|}
\hline \multicolumn{1}{|c|}{ MATERIAL } & PIEZAS & \multicolumn{1}{c|}{ LOCALIDAD } & AÑOS \\
\hline plata & 1 & Cepeda & 1743 \\
plata & 1 & Candelario & 1794 \\
"echura de oro" & 1 & Sequeros & 1776 \\
«echura de acero" & 1 & Villanueva & 1772 \\
\hline
\end{tabular}

LUGARES, CANTIDAD Y AÑOS PRIMERO Y ÚLTIMO EN QUE SE REGISTRA:

\begin{tabular}{|c|c|c|}
\hline LOCALIDAD & PIEZAS & $A \tilde{N} O S$ \\
\hline Sequeros .......... & 3 & 1702,1776 \\
\hline San Martín .. & 3 & 1704,1782 \\
\hline Cepeda ................... & 14 & 1708,1790 \\
\hline Alberca ............ & 6 & 1728,1755 \\
\hline Villanueva .......... & 1 & 1772 \\
\hline Miranda .............. & 1 & 1781 \\
\hline Candelario ....... & 1 & 1794 \\
\hline
\end{tabular}

PRECIO Y PESO:

En Sequeros 16 reales, 9 en la Alberca y 3 en Candelario.

El único documento en el que se declara, creemos, el peso corresponde a Cepeda, año 1743: "lignum de plata alibrado" (AHPS-P 6003, ff.61-63). Aunque nos queda la duda de si se estará aludiendo a la forma de libro, a manera de evangelios.

El uso de esta reliquia debía de ser muy común y en ocasiones diario: «lignuncruzis q traigo a la garganta a mi hijo". Cepeda, 1762 (AHPS-P 6007, f.39 y ss.).

El lignumcrucis podía ir como extremo de las siguientes alhajas: hilo de gabanzas (Cepeda); hilo sin más (Cepeda); manojito (Alberca) y rosario (Alberca). 
LABORES CON QUE SE ADORNA:

Filigrana: San Martín, año 1782 (1 ejemplar)

Engarce en plata, cinco ejemplares: uno en Cepeda, año 1708 tres en la Alberca, en 1728, 1729 y 1747 y uno en Sequeros, 1742.

Guarnición de plata (sin especificar): uno en Candelario, año 1794.

ELEMENTOS DE QUE SE COMPONE:

Delantera y Dorso: "[...] con reliquias al dorso, con cerco de plata de feligrana”. San Martín, 1782 (AHPS-P 6207 fol. suelto).

Cerco o Cerquillo: "lignum [...] pequeño con su cerquillo de plata". Sequeros, 1702 (AHPS-P 6236, f.108 y ss.). "lignun con cerco de plata". San Martín, 1725 y 1782 (AHPS-P 6199, f.102v y 6207, fol. suelto).

Aunque la forma habitual del lignum es la ovalada y redonda, se da también la variante esquinada y cuadrada. Así en la Alberca, año 1755 se cita un "ligno quadrado perteneciente a manojito" (AHPS-P 6111, f.81v): "Niño en cruzes con cerco de plata". Cepeda, 1747 (AHPS-P 6006, ff.77-81).

Asa: En Cepeda se consigna en el año 1782 un "lignun sin asa de plata mediano" (AHPS-P 6013, f.94 y ss.).

Cordón, Cinta o Listón: "lignun [...] y un cordón de seda grande". Cepeda, 1762 (AHPS-P 6007, f.167 y ss.). "[...] de echura de oro con su cinta 16 rs". Sequeros, 1776 (AHPS-P 6252, f.107v y ss.). "lignun con listón de platan. Cepeda, 1790 (AHPS-P 6015, f.79 y ss.).

Reliquias: Las reliquias ocupan el medio o centro del lignum y aunque no se especifica, es de suponer que siempre estuvieran protegidas por vidrieras. No siempre estas iban en la parte principal o cara, el único documento que habla explícitamente de reliquias las ubica en el lado posterior, dorso o espalda: "[...] con reliquias al dorso" San Martín, 1782.

Que el lignum no tiene siempre forma de joya-cruz se demuestra con ejemplos donde aparece enmarcado dentro de: a) Relicario: "lignun en un relicario de plata". Cepeda, 1708 (AHPS-P 5998, ff.136-140). b) Agnusdei: "lignun con agnusdein. Miranda, 1781 (AHPS-P 6151, f.242). c) Corazón: "Niño en cruzis, está en un corazonzito de plata". Cepeda, 1748 (AHPS-P 6004 , f.140v y ss.). "cruzita de lignum crucis perteneciente a corazoncito". San Martín, 1704 (AHPS-P 6195, f.34v y ss.). d) Caja: "Caxita de plata para un ligno en cruzis". Alberca, 1732 (AHPS-P 6103, f.80). “lignum grande con la caxa de plata". Cepeda, 1762 (AHPS-P 6007, f.167 y ss.).

TAMAÑOS:

Uno pequeño en Sequeros en 1702; uno mediano en Cepeda en 1781; otro grande en Cepeda en 1762. 
VOCES CON QUE SE DENOMINA:

\begin{tabular}{|l|c|l|l|}
\hline \multicolumn{1}{|c|}{ VOZ } & PIEZAS & \multicolumn{1}{|c|}{ LOCALIDAD } & \multicolumn{1}{|c|}{ AÑO } \\
\hline lignun cruzis & 3 & Sequeros & 1702,1742 \\
lignun cruzis & 3 & San Martín & 1704,1782 \\
lignun cruzis & 6 & Cepeda & 1708,1782 \\
lino en cruces & 1 & Cepeda & 1708 \\
ligno en cruzis & 6 & Alberca & 1728,1791 \\
ligno en cruzis & 1 & Villanueva & 1772 \\
ligno en cruzis & 1 & Miranda & 1781 \\
ligno en cruzis & 1 & Cepeda & 1790 \\
niño en cruzis & 5 & Cepeda & 1711,1753 \\
\hline
\end{tabular}

D. CRUZ DE OVIEDO.
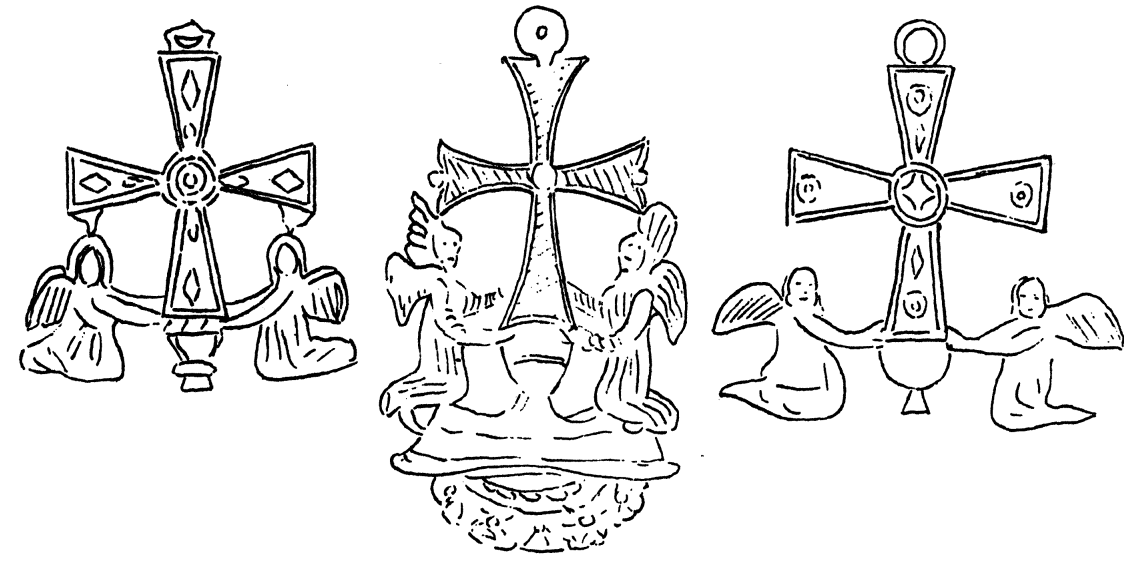

FIG. 13.-Cruces de Oviedo de labor fundida: a) Cruz de "metal" pequeña, perteneciente a extremo de rosario. Brazo y palo lisos con labores de rombo en el interior; el medio en forma de rosa. Ángeles tenantes y asa en forma de pedal de rastrillo de lino. Siglo XviII. b) Cruz de plata perteneciente a brazaleras. Labor incisa rayada sobre plancha maciza. Ángeles tenantes sobre peana de nubes. Asa redonda de lámina. Siglo XVIII. c) Cruz de "metal" pequeña como extremo de manojitos de corales. Motivos en rombos y rosas. Ángeles a los lados y asa redonda. Siglo XVIII (La Alberca, col. de los Hoyos Puerto). En Mogarraz, en algunos dijeros y brazaleras de vistas hay piezas similares a las $a$ y $c$. Los tres ejemplares son de factura bárbara y pensamos que de un taller no lejano a la capital asturiana o al menos con un conocimiento real de esa cruz. Aunque las tres piezas tienen motivos distintos, todos ellos se dan en el original de la Cámara Santa: las figuras $a$ y $c$ insisten en el planteamiento romboidal afiligranado y en los camafeos y gemas que la adornan, la $b$, quiere dar la impronta en la labor de filigrana en malla que presenta la cara de la cruz ovetense. 
LUGARES Y AÑOS PRIMERO Y ÚLTIMO EN QUE SE REGISTRA:

\begin{tabular}{|c|c|c|}
\hline LOCALIDAD & PIEZAS & $A \tilde{N} O S$ \\
\hline Alberca ............. & 29 & 1750,1775 \\
\hline Cepeda & 3 & 1772,1788 \\
\hline
\end{tabular}

MATERIAL DE QUE SE COMPONE Y PRECIO QUE ALCANZA:

Dos piezas de plata: una en la Alberca en 1770 y la otra en Cepeda en 1778. En la Alberca se llega a tasar la cruz de Oviedo en una cantidad máxima de 100 reales vellón, 8 reales la media y 4 la mínima.

\section{ELEMENTOS QUE SE DESCRIBEN EN ESTE SIGLO:}

Ángeles: El elemento más característico de esta cruz es el que lleva a ambos lados del palo, en la parte llamada "el liso", los dos ángeles o mancebos arrodillados y tenantes, legendarios autores de la cruz.

Los testimonios escritos que hacen referencia a este elemento corresponden a la Alberca: "obiedo con ángeles a los lados, diez reales de vellón". 1745 (AHPS-P 6107, f.172v): “Obiedo con los ángeles”. 1755 (AHPS-P 6111, f.79).

Por su tamaño la cruz puede ser: pequeña, un ejemplo en la Alberca, 1744 y grande o doble, con tres ejemplos en la Alberca en 1743 y 1761 y uno en Cepeda en 1778.

Esta advocación parece muy floreciente en la Alberca, lugar donde llega a acumularse hasta cinco veces en una misma persona: "cinco cruzes de Obiedo". Año 1781 (AHPS-P 6120, f.100). Se da algún otro ejemplo de tres cruces y cinco casos de dos y, desde luego, era muy frecuente tener una. Suelen ir colocadas como extremos de: manojito, manojo de corales e hilito pequeño. Se escribe siempre como cruz de Obiedo.

E. CRISTO DE BURGOS.

Los primeros testimonios documentales de esta devoción en una cruzjoya corresponden a la tercera década del siglo XVIII en la serranía de Francia y, aunque se desarrolla tímidamente, llega luego a florecer con ventaja sobre las demás advocaciones de la cruz en la centuria siguiente.

LUGARES, CANTIDAD Y AÑOS PRIMERO Y ÚLTIMO EN QUE SE REGISTRA:

\begin{tabular}{|c|c|c|}
\hline LOCALIDAD & PIEZAS & $A \tilde{N} O$ \\
\hline San Martín ........ & 1 & 1736 \\
\hline Cepeda ............ & 9 & 1740,1798 \\
\hline Alberca & 7 & 1747, 1786 \\
\hline
\end{tabular}




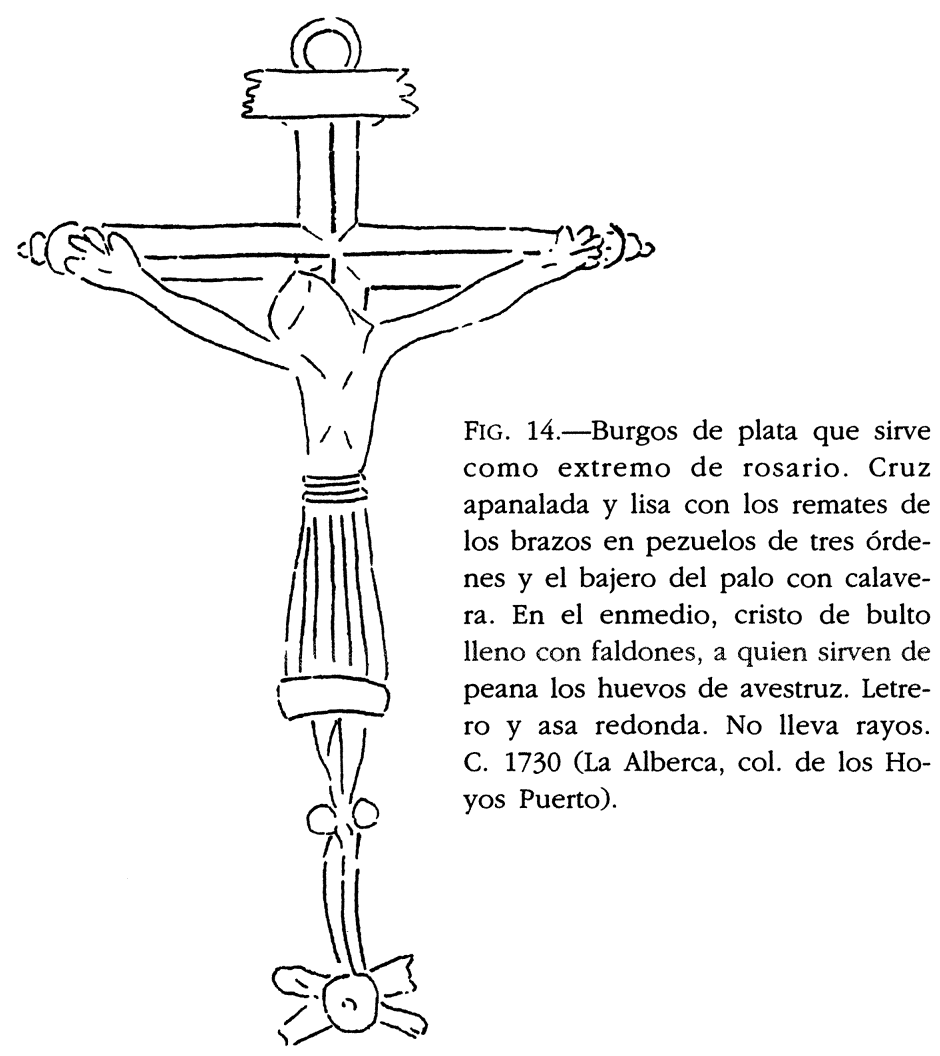

Sólo se especifica como material la plata en seis casos: tres en Cepeda en 1740 y 1798 y tres en la Alberca en 1747 y 1776.

ELEMENTOS DE QUE SE COMPONE:

Cordón: Aunque en este siglo los documentos escatiman las descripciones y labores de esta hechura, solamente se habla en dos ocasiones del cordón que acompañaba a la figura y por tanto elemento muy secundario, son sin embargo inconfundibles las características iconográficas que presenta. El cristo aparece siempre con faldones o toballa, y bajo sus pies no falta -a modo de exvoto- el exótico tic identificador de dos huevos de avestruz.

Los ejemplos iconográficos más antiguos en el siglo xviII, llevan además en la zona de la cruz, conocida como "el liso", un tarjetón con el nombre de la advocación y en la base, haciendo las veces de peana, una calavera. A partir del siglo XIX el cristo queda casi neutralizado por la ampulosidad de la cruz y la magnificencia de los rayos que de ella salen. Al exvoto y tarjetón se añade, muy andado ya el siglo XIX, un corazón. 
En cuanto al cordón como elemento, tenemos las siguientes citas: Cepe$\mathrm{da}$, año 1764: "[...] con cordón perteneciente a cristo de Burgos" (AHPS-P 6000 , f.212 y ss.). También en Cepeda, el año 1798, se registra "un cordón azul con cristo de Burgos" (AHPS-P 6017, f.187 y ss.).

El cristo de Burgos lo llevan las serranas en las siguientes alhajas: en hilo de coral, en Cepeda y Alberca entre 1762 y 1778; en agnus, en Cepeda, año 1762; en una medida en San Martín, 1736: "una medida con cristo de Burgos".

Aparece de tamaño pequeño dos veces en la Alberca, y uno grande en Cepeda. En estas localidades una misma persona suele disfrutar de dos hechuras de esta advocación.

\section{F. CRUZ DE JERUSALÉN O ENCOMIENDA DE SAN JUAN.}

LUGARES DONDE SE ENCUENTRA POR PRIMERA Y ÚLTIMA VEZ:

\begin{tabular}{|c|c|c|}
\hline LOCALIDAD & PIEZAS & $A \tilde{N} O$ \\
\hline Cepeda . & 1 & 1705 \\
\hline Miranda . & 2 & 1736,1783 \\
\hline Alberca ......... & 4 & 1776,1782 \\
\hline Candelario ... & 1 & 1784 \\
\hline Villanueva ...... & 1 & 1794 \\
\hline
\end{tabular}

No tenemos noticia del material empleado en esta variante, aunque es de suponer que predominase la plata. Solo se especifica en el documento de Candelario: "cruz de Jerusalén anacarada 12 quartos" (AHPS-P 1141, f.142 y ss)

ELEMENTOS DE QUE CONSTA:

Estremos, que en la cruz son elemento de guarnición indispensable. En documento mirandeño del año 1783 la cruz de Jerusalén tenía "los estremos de plata" (AHPS-P 6152, f.240v).

Flores: En Miranda, en el Inventario del Humilladero, año 1736, se nombra entre otras alhajas del Cristo "una cruz de Jerusalén con flores de nácar para el altar" (APM Inv. Humilladero año 1637, s.f.). Probablemente se trataba de una pieza grande para que resultara bien visible a la devoción de los cofrades de la Veracruz. Las flores de nácar que la adornaban formarían parte de ella, aunque no debemos entender esta voz, "flores", en el sentido técnico con que la usan los plateros, como sinónimo de "caramullo" o adorno que va en el interior de una pieza llenando su hueco, que suele ser siempre afiligranado. Como es evidente por la cita, esta cruz no iba destinada al adorno personal. 
Embutidos: En documento de la Alberca de 1782 (AHPS-P 6120, f.2), se alude por dos veces a una cruz de Jerusalén "grande con embutidos". En este caso parece que los brazos y palo eran "llenos" o al menos lisos y llevaban, a modo de cubierta, una guarnición, probablemente de un material más noble y labor calada.

El precio en que se tasan estas cruces en el siglo XVIII oscila entre los 12 reales de Miranda y los 6 reales de Villanueva, según constancia documental. Aparece la forma estrellada de esta cruz en la Alberca, año 1776 (AHPS-P 6118, f.161). La Alberca nos da también la proporción de esta cruz que puede ser: grande, año 1782 y pequeña en ese mismo año (AHPS-P 6120, f.2). Asímismo, en esta localidad se alcanza el número mayor de cruces acumuladas en una sola persona, que llegó a poseer tres de Burgos.

\section{SIGLO XIX}

\section{Cruces en general}

Contamos en este siglo 139 documentos, referentes a la cruz, que posibilitan una visión bastante completa de lo que esta joya significó, dentro de los elementos del adorno femenino, y los cambios formales que sufrió. En este tiempo, la cruz se refugia en el cuello de la mujer, siguiendo la tónica general de acortamiento de collares y otros adornos que antes llegaron casi hasta los pies y ahora no pretenden bajar del pecho. El tamaño se reduce, pues, considerablemente - sólo continúan sin alteración las "echuras" de advocaciones concretas-, y el carácter protector que tenían la mayoría de las joyas, perdido casi por completo en este siglo, no hizo excepción con las cruces, que quedan ahora en mera joya o fórmula de adorno. Este paso se acusa materialmente en el cambio de la plata por el oro, que va a predominar como gusto casi exclusivo, olvidando aquellas piezas anteriores no susceptibles de mejorar con un humo de oro, si las formas son demasiado rebeldes al enmascaramiento.

LUGARES, CANTIDAD Y AÑOS PRIMERO Y ÚLTIMO QUE SE REGISTRAN:

\begin{tabular}{|c|c|c|}
\hline LOCALIDAD & PIEZAS & $A \tilde{N} O S$ \\
\hline Candelario ........ & 65 & 1801,1863 \\
\hline 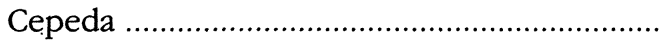 & 22 & 1800,1840 \\
\hline Miranda ........................ & 17 & 1814,1848 \\
\hline Monforte ............ & 14 & 1809,1856 \\
\hline San Martín ........ & 9 & 1804,1829 \\
\hline Alberca ........... & 4 & 1802,1806 \\
\hline 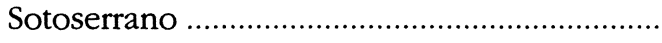 & 3 & 1828,1838 \\
\hline Tamames .................... & 2 & 1872 \\
\hline Cabaco .............. & 1 & 1816 \\
\hline Garcibuey ............. & 1 & 1806 \\
\hline Villanueva ........... & 1 & 1836 \\
\hline
\end{tabular}


MATERIAL DE QUE SE COMPONEN:

\begin{tabular}{|l|c|l|l|}
\hline \multicolumn{1}{|c|}{ MATERIAL } & PIEZAS & \multicolumn{1}{|c|}{ LOCALIDAD } & \multicolumn{1}{|c|}{ ANOS } \\
\hline oro & 10 & Monforte & 1809,1856 \\
oro & 10 & Candelario & 1827,1841 \\
oro & 8 & Cepeda & 1803,1847 \\
oro & 5 & San Martín & 1814,1825 \\
oro & 3 & Miranda & 1840,1843 \\
oro & 2 & Tamames & 1872 \\
oro & 1 & Alberca & 1802 \\
oro y piedras & 1 & Cepeda & 1800 \\
oro y piedras falsas & 1 & Cepeda & 1821 \\
oro y aljófar & 14 & Candelario & 1865 \\
plata & 2 & Candelario & 1801,1863 \\
plata & 1 & Sotoserrano & 1828,1829 \\
plata & 1 & Caberca & 1804 \\
plata & 1 & Garcibuey & 1816 \\
plata & 1 & Miranda & 1806 \\
plata & 2 & Cepeda & 1812 \\
plata de "Córdova" & 1 & Candelario & 1847 \\
plata seca & 1 & Cepeda & 1816 \\
plata ahumada & 5 & Candelario & 1814 \\
plata dorada & 1 & Miranda & 1805,1823 \\
plata sobredorada & 1 & Miranda & 1842 \\
plata y piedras & 1 & Cepeda & 1841 \\
p. ahumada y piedras & 1 & Cepeda & 1847 \\
piedras blancas & 1 & Candelario & 1800 \\
piedras verdes & 1 & Alberca & 1802 \\
piedras verdes & 1 & Miranda & 1803 \\
esmeraldas & 1 & Miranda & 1880 \\
diamantes & Candelario & 1841,1880 \\
diamantes & Miranda & 1863 \\
"metal" & 1842 \\
\hline
\end{tabular}

PRECIOS EN QUE OSCILAN LAS CRUCES:

\begin{tabular}{|c|c|c|c|}
\hline LOCALIDAD & MÁXIMO & MEDIO & MÍNIMO \\
\hline Candelario.. & $1.500 \mathrm{rs}$ & $68 \mathrm{rs}$ & $5 \mathrm{rs}$ \\
\hline Miranda .............. & 500 rs & $158 \mathrm{rs}$ & $16 \mathrm{rs}$ \\
\hline Sotoserrano ....... & 300 rs & - & 90 rs \\
\hline San Martín .. & 260 rs & 160 rs & $20 \mathrm{rs}$ \\
\hline 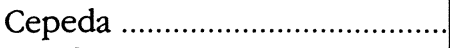 & $200 \mathrm{rs}$ & $80 \mathrm{rs}$ & $14 \mathrm{rs}$ \\
\hline 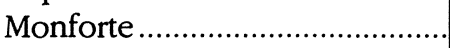 & $120 \mathrm{rs}$ & 80 rs & $20 \mathrm{rs}$ \\
\hline Alberca & - & - & $6 \mathrm{rs}$ \\
\hline
\end{tabular}


ELEMENTOS DE LA CRUZ QUE APARECEN ESPECIFICADOS EN LOS DOCUMENTOS:

Reliquias: Este elemento que ocupa la parte central de la cruz y suple al crucifijo, apenas sobrevive al siglo, y eso con un solo ejemplo en la Alberca, año 1806. Se supone y se impone con este elemento la variante de cruz de ánima para acoger en ella reliquias: "cruz de reliquia con su dosel" (AHPS-P 6127, f.35).

Botón: Lo que dijimos del lazo, respecto a la cruz en el siglo XVIII, lo afirmamos ahora del botón, que va, generalmente, uniendo la cruz con el lazo e incluso a veces supliéndolo por estrangulamiento. En ocasiones se entiende también por botón la rosa o estrella abotonada que se coloca en el llamado enmedio en ejemplares que no llevan cristo y donde los brazos y palo no son de ánima sino macizos. El texto que nos proporciona Candelario no nos sacaría de duda: "dos cruzes de botón de plata 16 rs", año 1818. No sabemos si las cruces eran denominadas de "botón" o, por el contrario, el botón que llevaban las cruces era de plata; la grafía de la época no ayuda a despejar la duda (AHPS-P 1148, 12 fol.)

Lazo: Es el elemento cimero del tipo de cruz "rica" que desdibuja, junto con las almendras o almenas, el esquema claro de la cruz en aras de la ornamentación por una alteración de valores. Aparece en este siglo la variante de "lazo" en documentos candelarios desde el año 1801 al 1829. En uno de ellos se describen "tres cruces de lazo con piedras verdes", año 1802 (AHPS-P 1143, s.f.). También San Martín del Castañar avala ya la moda de la cruz de lazo en la Sierra de Francia, año 1825, variante que había llegado como novedad a Candelario en el último decenio del siglo anterior: "cruz de lazo grande de oro" (AHPS-P 6216, f.80v). Un segundo documento de San Martín, en 1829, confirma la presteza de esta villa por todo lo novedoso: "cruz de lazo de plata, 20 rs" (AHPS-P 6216, f.85v).

Rosetas: Salvo los dos elementos anteriores - botón y lazo- todos los demás adolecen de un verdadero sentido funcional, debiendo considerarse más bien adornos importantes que solían ir enmascarando sus elementos sustentantes; hasta tal extremo han cedido las formas a la guarnición.

Las rosetas son un tipo de remate o extremo que corona los brazos y palo y uno de los motivos ornamentales más universal para representar el sol firme o quieto. La Sierra de Francia no escatima ninguna parcela del arte popular para representarlo (se encuentra en vigas y tramones, en arcas nupciales, en bordados y, desde luego, en las joyas). Los plateros actuales de la Sierra denominan a este elemento estrella, y los de Ciudad Rodrigo continúan manteniendo la voz rosa: "cruz afeligranada con dos rosetas", Miranda, 1812 (AHPS-P 6919, s.f.).

Dosel: Se describe en la Alberca en 1806 una "cruz de reliquia con su dosel" (AHPS-P 6127, f.35). 
Almenas y Almendras: Las almenas y almendras suelen ir colgando, como ya hemos visto, de los brazos y palo bajero, en número de una, dos o tres. En San Martín, año 1821, se documenta una cruz de «echura portuguesa que tiene su almendra" (AHPS-P 6215, f.21v). En Tamames, año 1872, el Inventario de $N^{a}{ }^{a}{ }^{a}{ }^{a}$ del Rosario cita "una cruz de oro perteneciente a hilo de oro con una almena abajo" (APM Inv. Rosario, s.f.). Las almenas y almendras sustituyen a las medallas que adornaban los brazos y pies de las cruces en los siglos XVII y XVIII. Cuando estos pendientes o almenas no tienen una forma clara o definida para los tasadores se describen sin más como "alhajas". Así se registra en Cepeda en el año 1804: "cruz engastada, con tres alajitas afiligranadas" (APHS-P 6019, f.193).

LABORES CON QUE SE ADORNAN LAS CRUCES:

Calada: En Candelario, año 1862, se describe un "Cristo calado de plata de diez y seis reales" (es característica esta labor en los cristos de Burgos).

Filigrana: En 1812 y 1843 aparecen dos ejemplos de cruz afiligranada. En Monforte de la Sierra en 1825 y en Sotoserrano en 1838 se pagaron 300 reales por una cruz grande de oro de filigrana (La labor calada puede ser de filigrana o recortada).

Maciza: La cruz de labor maciza no es frecuente en el siglo XIX. El horror a la supeficie lisa o entera, aunque esté labrada a martillo, será desde ahora insuperable. Candelario nos proporciona dos últimos testimonios de labor llena o maciza. El primero corresponde al año 1816: "cruz maciza de plata dorada $38 \mathrm{rs}$ ". El segundo, de 1832: "cruz maciza dorada 30 rs".

Engastada: No tenemos noticia sobre el tipo de engaste y su ubicación. Era de plata y solía guarnecer o cubrir el ánima de la cruz. Quedan dos ejemplos en Cepeda, año 1804 y Monforte en 1839.

Echura portuguesa: En 1821 se registra en San Martín una "cruz de oro portuguesa mediada que tiene su almendra" (AHPS-P 6215, f.21v) ${ }^{13}$.

LA CRUZ FORMA PARTE DE:

Hilo: Así aparece en Miranda en 1841 y en Tamames en 1872.

Gargantilla: Se documenta en Cepeda en 1816 y 1847. En Candelario en 1863 un hilo se adornaba llevando por extremo una cruz de aljófar.

Medallón: Miranda en 1842 registra uun medallón en el que está puesta una cruz sobredorada". ¿Podría tratarse de una patena? (AHPS-P 6917, f.161).

Collar: En inventario de Cepeda, año 1805, se cita "cruz de oro grande con collar de perlas nuevo" (AHPS-P 6019, f.175 y ss.).

13 Era costumbre, entre la nobleza serrana pasar temporadas de esparcimiento en zonas de Portugal, especialmente si tenían balneario, y traer a la vuelta alguna joya y capricho. Esta tradición se prolongaría hasta bien entrado el siglo actual. 

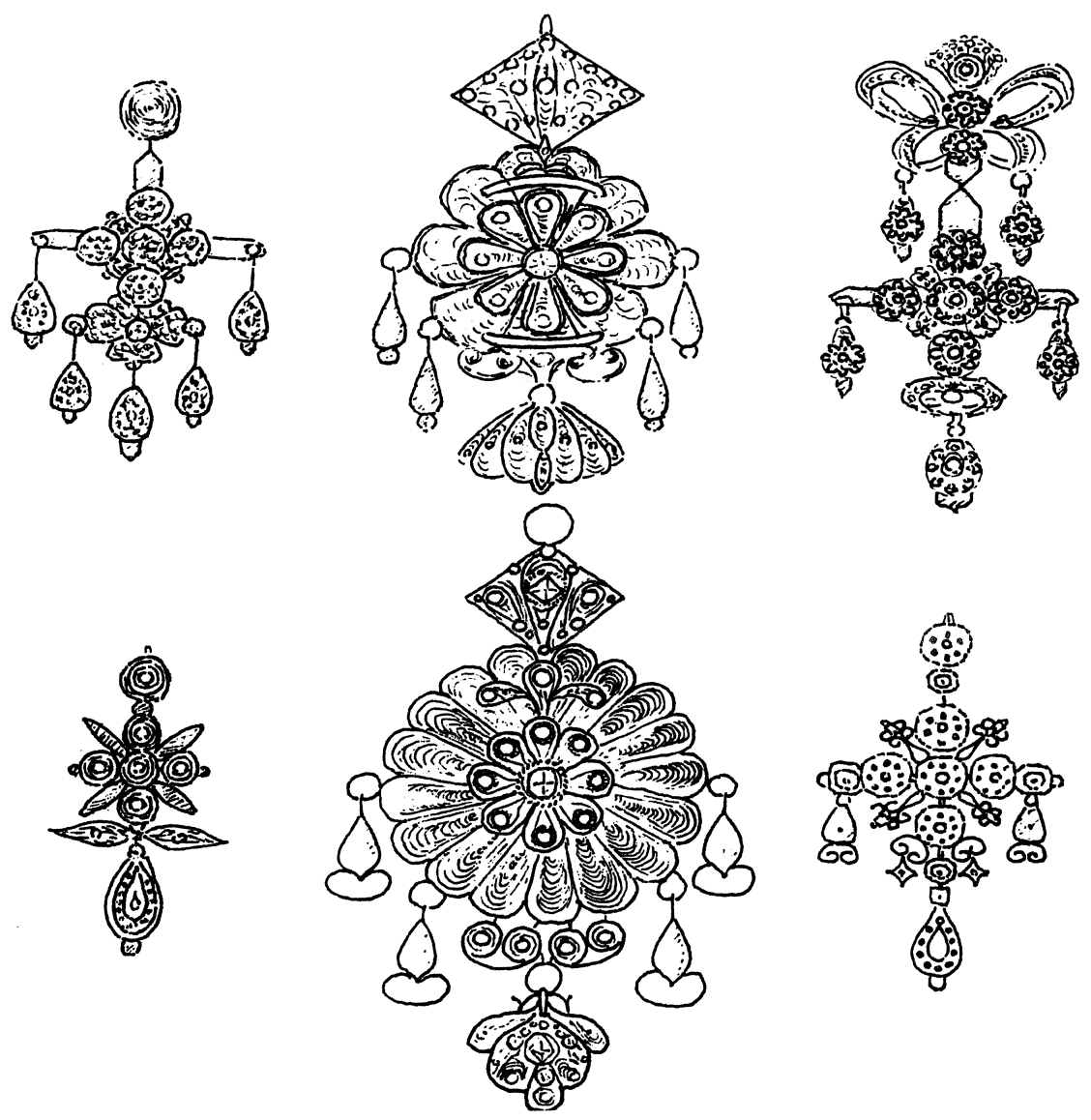

FIG. 15--Galápagos, cruces tembladeras o filigranas. a) Cruz ede tres lazás" de filigrana de oro; va como extremo de hilo de granos. La lazada de arriba es una cabeza afiligranada, las otras dos hacen la estrella o cruz doble. La de arriba con base de picos lisos, cuatro cabezas con diamantes embutidos y cuatro piernas que hacen los rayos de filigrana. La lazada chica o bajera es de mariposa o cruz trebolada y calada, con azafate en el centro. Cincos péndolas sobre picos lisos almendrados hacen la higa y la mano de Fathma (La Alberca, col. Serrano Becerro). b) Galápago de filigrana de oro de los llamados ade teja. Va como extremo de hilo de granos lisos de oro. Tiene similares características y técnica a la pieza e estrella doble central, lazo de teja péndola central en abanicos haciendo higa y las de los lados lisas y almendradas pieza $e$ : estrella doble central, lazo de teja, péndola central en abanicos haciendo higa y las de los lados, lisas y almendradas
(La Alberca, col. Serrano Becerro). c) Cruz tembladera de oro ede tres lazás"; va como extremo de un hilo de granos lisos. El orden cimero es de lazo achico de mariposar. El central, cruz con tres picos lisos como base y estrella de cuatro cabezas - haciendo la cruz - con chispas embutidas y los rayos, cuatro piernas de filigrana. La lazada bajera, greca afiligranada y chispas en medio. Cinco péndolas - dos de la mariposa, dos de los picos de la cruz y una del lazo bajero- en cabezas con chispas de diamantes formando la mano de Fathma y, cada una de por sí, la higa (La Alberca, col. Serrano Becerro). d) Filigrana de oro que va como extremo de hilo de granos lisos. La lazada de arriba, una cabeza de casco liso con chispas de diamantes embutidas. La cruz, de cuatro granos con piedras de francia y los rayos, cuatro copetes de filigrana. La lazada bajera, dos piernitas de filigrana, unidas por azafate y una gran péndola con greca de chispas de francia más un pico liso en el extremo, haciendo la higa (La Alberca, col. Serrano Becerro). e) Galápago de teja de filigrana de oro; va como extremo principal de hilo de granos de casco liso. Estrella de dos órdenes con piernitas de filigrana: el cimero con pezuelos que hacen la cruz y los rayos y dentro cordoncillo alrededor en forma de lignumcrucis. El cuadro de la lazada con los mismos adornos que la estrella. Cinco péndolas: la central de filigrana en higa y las laterales lisas (La Alberca, col. Serrano Becerro). f) Crucita de oro con tembladeras; va como extremo de hilito de oro. Lazo, estrella o cruz con sus rayos con caramullos, y picos de la cruz lisos, de los que cuelgan dos almendrillas a los extremos. La péndola central con cascos embutidos de chispas de diamantes (La Alberca, col. Serrano Becerro). Todas las piezas, aunque arrastran modelos dieciochescos, son de hechura posterior a la segunda mitad del siglo XIX. 
De cuello de abajo: Siguen registrándose piezas, ya en estas fechas arcaizantes, como la vuelta grande o de abajo, que se utiliza en el traje de Vistas: "una cruz de abajo". Cepeda, 1830 (AHPS-P 6904, f.suelto).

Brazalera: También, como en el apartado anterior, aquí se acogían piezas —en este caso cruces - de hechura antigua "ya muy traidas", como en estos dos ejemplos de Monforte: "Cristo de oro dentro de caja de plata perteneciente a brazalera". Año 1833 (AHPS-P 6920, f.25v). Año 1845: "Cristo peteneciente a brazalera" (AHPS-P 6921, ff.11-14v).

Rosario y Corona: Dos ejemplos en Monforte, años 1833 y 1845, donde se alude a la cruz como extremo de corona. En Candelario en 1863 aparece una cruz como remate de rosario.

Por su tamaño la cruz puede ser pequeña con un ejemplo en la $\mathrm{Al}$ berca en 1803 y Miranda en 1814. Mediana: dos en San Martín, año 1821. Grande o doble: dos en Monforte, 1825 y 1826 y uno respectivamente, en San Martín, 1825, Candelario, 1832, Sotoserrano, 1838, y Miranda, 1840.

En esta centuria la cruz sigue siendo imprescindible como regalo: a) de Vistas. Candelario en los años 1805 y 1863 tiene documentadas cruces como regalo de Vistas. b) Arras: También Candelario conserva documentos donde se ofrecen cruces en arras. c) Dote: asímismo, Candelario incluye la cruz como regalo dotal en documento de 1829 y Miranda en los años 1842 y 1845 , en este caso entre familias nobles ${ }^{14}$.

\section{ADVOCACIONES}

A. CRUZ DE CARAVACA.

En el siglo XIX pervive esta advocación en 9 documentos en los años y lugares siguientes:

\begin{tabular}{|c|c|c|}
\hline LOCALIDAD & PIEZA & $A \tilde{N} O S$ \\
\hline Alberca & 2 & 1801 \\
\hline Cepeda. & 5 & 1803,1853 \\
\hline Monforte ............. & 1 & 1809 \\
\hline Candelario ......... & 1 & 1861 \\
\hline
\end{tabular}

14 Que la cruz como regalo en fechas señaladas era o podía ser una razón de peso para convencer a la enamorada e incluso para enamorar con ella, si la cruz era considerada rica, lo demuestra la canción mirandeña de "la Tortolica", una de cuyas estrofas dice: "si quieres que te quiera me has de dar antes/jubón de terciopelo, cruz de diamantes". 

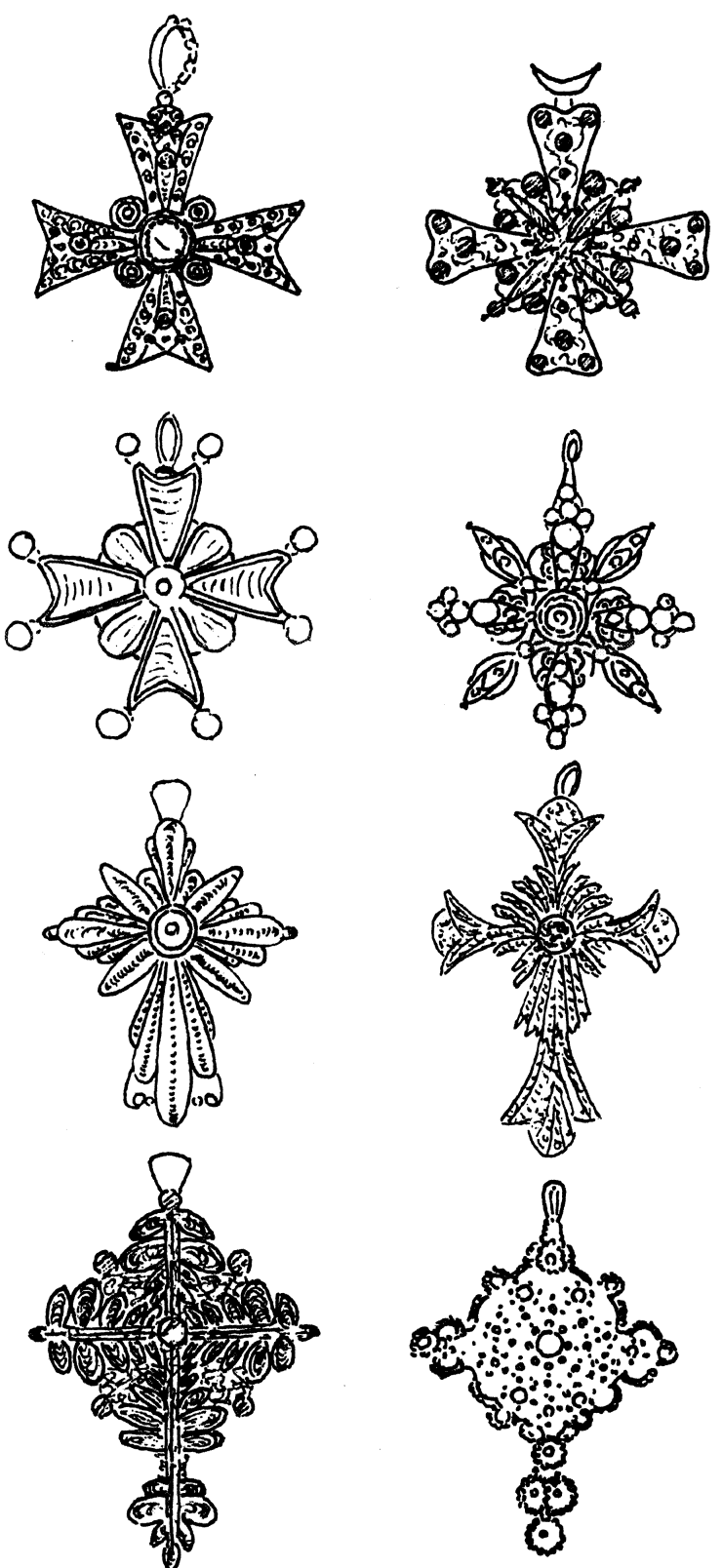

FIG. 16.-Cruces-encomienda. Estas pequeñas cruces de cuello que forman parte como extremo de los denominados hilos de oro, se conocen también popularmente como veneras. Surgen hacia el último decenio del siglo XIX en su hechura actual y llegan vivas hasta nosotros, desbancando los demás arquetipos tradicionales. En estas figuras se compendian todas las variantes que podemos encontrar en cualquier localidad serrana. 
MATERIAL DE QUE SE COMPONE:

\begin{tabular}{|l|c|l|c|}
\hline \multicolumn{1}{|c|}{ MATERIA } & PIEZAS & LOCALIDAD & AÑOS \\
\hline "metal" & 2 & Alberca & 1801 \\
plata & 1 & Cepeda & 1803 \\
piedras diferentes & 1 & Cepeda & 1823 \\
\hline
\end{tabular}

No hay noticias concretas sobre las variantes de hechura, labores y elementos diversos que compongan esta cruz. Solamente la cita de Cepeda del año 1823 nos describe la de Caravaca con un cierto afán de concretar su forma: "una cruz de Alcarabaca con diferentes piedras y su cabeza 60 reales". (AHPS-P 6024, f.23 y ss.). Se trata de una variante rica al estilo de las cruces "de lazo y botón", inventariadas anteriormente. Lástima que no contemos con ninguna joya-testigo de Caravaca de estas características.

La cruz de Caravaca puede formar parte como extremo en: hilos de corales (Cepeda), manojito de corales (Monforte), alhaja (Cepeda), y rosario (Candelario).

La voz con que se denomina en todos los documentos es cruz de Alcarabaca.

B. CRUZ DE SANTO TORIBIO.

Cuatro documentos de Cepeda, entre los años 1803 y 1823, conservan la advocación de Santo Toribio. Parece que esta cruz se refugió -al menos en Cepeda- en la corona como su remate, o bien como uno de sus pendientes más importantes, según se desprende de tres de los cuatro documentos, años 1806, 1823. Una de ellas se describe como engarzada en plata" (1823), otra como cruz de tamaño "grande" (1823). (AHPS-P 6024, f.23 y ss.)

\section{LIGNUMCRUCIS.}

LUGARES, CANTIDAD, PRECIOS Y AÑOS PRIMERO Y ÚlTIMO EN QUE SE REGISTRA:

\begin{tabular}{|l|c|c|c|c|}
\hline \multicolumn{1}{|c|}{ LOCALIDAD } & PIEZAS & PRECIO MÁX. & PRECIO MÍN. & AÑOS \\
\hline Alberca & 3 & $8 \mathrm{rs}$ & - & 1802,1806 \\
Monforte & 3 & $25 \mathrm{rs}$ & $10 \mathrm{rs}$ & 1825,1830 \\
\hline
\end{tabular}

En Monforte, año 1830, se cita un lignumcrucis "todo de plata" (AHPS-P 6186, f.219 y ss.). Ese mismo lignum era de figura grande y pendía también de una cadena de plata. En la Alberca en 1802, otros dos ejemplos nos describen esta cruz relicario pendiente de cadena y formando parte de brazalera o de dijero de niño: "dos linus cruzes y su cadena de plata cada 
uno" (AHPS-P 6126, f.94). Otro lignum, también albercano, estaba en caja de plata: "Niño en cruzis en caja de plata, ocho". Esta caja es la armación o estructura formal entre cuyas paredes se encuadran las reliquias del lignum. Ningún dato aclara en el siglo XIX las formas que adopta esta caja. En el siglo xviII se daban las variantes redonda, oval y cuadrada.

En la Alberca una sola persona llega a poseer dos lignumcrucis.

VOCES CON QUE SE ACOSTUMBRA A LLAMAR ESTA CRUZ:

\begin{tabular}{|c|c|c|c|}
\hline MODALIDAD & LOCALIDAD & PIEZAS & $A \tilde{N} O S$ \\
\hline ligno en cruz & Monforte & 1 & 1825 \\
\hline lignum cruz & Monforte & 1 & 1830 \\
\hline linus cruzes & Alberca & 2 & 1802 \\
\hline niño en cruz & Monforte & 1 & 1830 \\
\hline niño en cruzis & Alberca & 1 & 1806 \\
\hline
\end{tabular}

D. CRUZ DE JERUSALÉN.

Solo un documento sobre esta cruz llega a nosotros en el siglo XIX y corresponde a Candelario, año 1832: "cruz grande de Jerusalén cuarenta reales" (AHPS-P 1153, ff.75v-76v).

E. CRUZ DE OVIEDO.

La cruz de Oviedo se extingue en los documentos de la Sierra en 1806. Ningún dato que describa con detalle la belleza de esta cruz. Sabemos que en la Alberca una de ellas iba como extremo en un hilo (1804).

Se pueden encontrar hasta dos ejemplares de esta cruz en un solo collar y su precio suele ser de cuatro reales. En la Alberca se conservan cuatro piezas datadas en 1801 y 1804, y dos en Cepeda entre 1804 y 1806.

Se utiliza siempre en la Alberca la grafía "Obiedo" y en Cepeda "Oviedo".

F. CRISTO DE BURGOS.

Esta variante se mantiene en la documentación de la Sierra hasta 1853 en quince documentos: catorce localizados en Cepeda en los años 1803 y 1853 y uno en Monforte en 1825.

Cuatro concretan su hechura como de plata: tres en Cepeda, 1803, 1845 y el de Monforte. Es característica de esta advocación en las joyas-testigo que se conservan, la labor denominada "de huecos", como queda atestiguado en Cepeda, año 1847: "dos cristos de Burgos huecos" (AHPS-P 6933, f.s.).

El único elemento principal que mencionan los textos es la propia $\mathrm{cruz}$ sin más, y es que el Cristo de Burgos en el siglo XIX - y ya en casi to- 


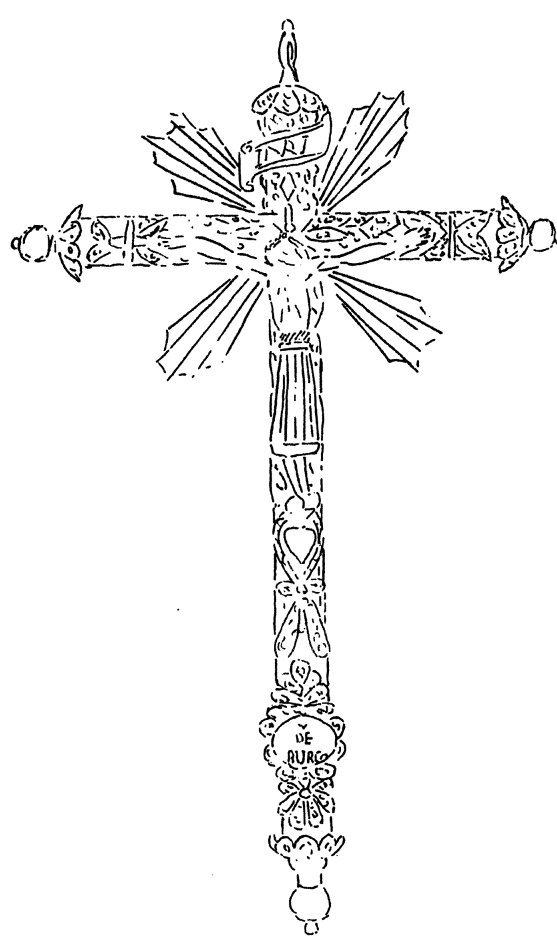

FIG. 17.-Crucifijo de Burgos de plata (va suelto). Cruz con armación embutida lisa y sobre ella un sobrecuerpo de mariposas o lazos calados, todo unido por azafates y guarnición de caramullos o flores. Cerco de rayos de a cinco y a seis, lisos y rayados alternando, a martillo. Letrero enrollado. En el medio Cristo, con hechura de bulto hueco, apoya los pies en los huevos de avestruz. El resto del palo lo ocupa un corazón enmarcado en gran lazo y debajo cartela con la leyenda: DE/BURGOS, entre abanico de filigranas. Los extremos también de filigrana, coronados por grandes cascos lisos. Ultimo tercio del siglo XIX (La Alberca, col. de los Hoyos Puerto).

das las hechuras del XVIII - desdibuja el resto de sus elementos a favor de una cruz ampulosa llena de huecos donde apenas hay lugar para el crucifijo, que se queda en desventaja con la cruz: "Cristo de Burgos con cruz, todo de plata". Cepeda, 1803 (AHPS-P 6019, f.175 y ss.). Como elemento menor y guarnición aparecen las almendras o almendrillas que cuelgan de los brazos y palo: "Cristo con almendrillas". Cepeda, 1810 (AHPS-P 6023, f.67).

La cruz de Burgos en este siglo va formando parte de una corona (Cepeda 1853) y como uno de los dijes cristianos en una brazalera de Monforte en el año 1825 . El precio máximo en que se tasa alcanza en Cepeda los 20 reales, y la mayor cantidad de cruces que llega a acumular entre sus joyas una sola persona es de dos: "una cruz grande" es la única referencia al tamaño en Cepeda y año 1829 (AHPS-P 6023, f.118 y ss.).

\section{G. CRISTO DE VALENCIA.}

Esta advocación de efímera vida en la Sierra aparece por primera y última vez en documento de Cepeda, año 1819. Se trata de cuatro ejemplares pertenecientes todos ellos a una misma colección: "cuatro cristos 


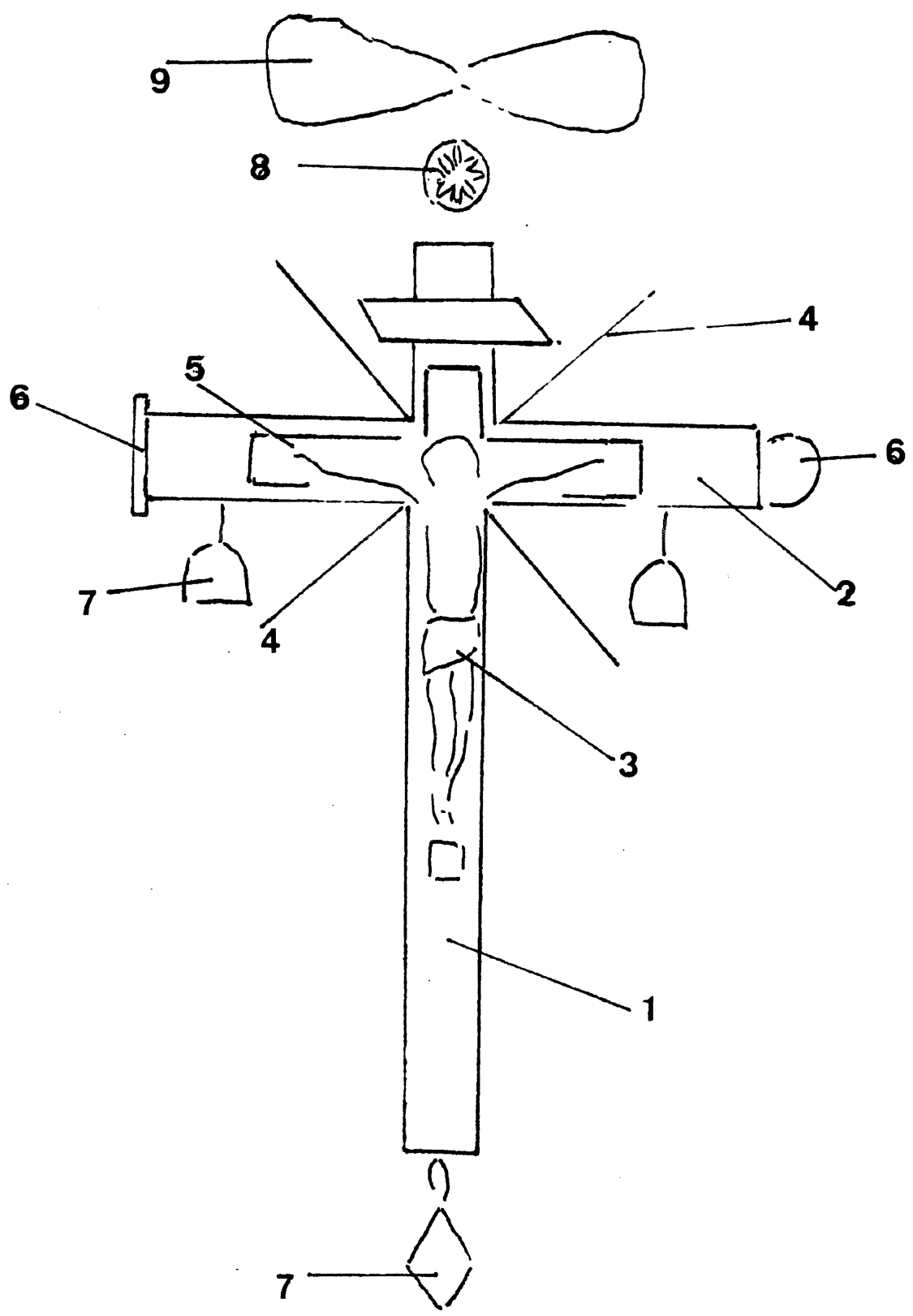

FIG. 18.-Siglo XIX. Esquema de la cruz. Elementos y sus nombres. 1) Palo, cruz o liso: macizo, calado, afiligranado, engastado. 2) Brazos. 3) Cristo: macizo y hueco. 4) $R a$ yos (voz en uso entre los plateros actuales). 5) Reliquias. 6) Estremos: de botón, y de rosetas. 7) Pendientes. 8) Cabeza o botón. 9) Lazo. 
de Valencia a diez reales cada uno" (AHPS-P 6203, f.118 y ss.). Ninguna característica se desvela acerca de este Cristo, elementos, labores, etc. ${ }^{15}$

H. CRISTO DE ZALAMEA.

Parecidas conclusiones a las de la advocación anterior deducimos del llamado Cristo de Zalamea. Contamos con un solo documento en Monforte de la Sierra en el año 1830: "Cristo de Zalamea de plata 20 reales" (AHPS-P 6186, f.245 y ss.). Esta efigie resulta más familiar en la Sierra de Francia que la de Valencia, pues ya en textos del siglo XVIII se parangonaba el Cristo de Zalamea con el del Humilladero de Miranda del Castañar, como salidos de la misma mano ${ }^{16}$.

ANTONIO CEA GuTIÉRREZ

Departamento de Antropología Instituto de Filología. CSIC.

Se estudia la cruz-joya dentro del vasto y complejo ámbito de la indumentaria tradicional en el área de la Sierra de Francia y Candelario (Salamanca). A través de la documentación de archivo, que abarca desde los últimos años del siglo xvi hasta la octava década del XIX, el trabajo de campo y la observación de la pieza-testigo se analizan - desde una óptica etnohistórica- los aspectos materiales y formales de la cruz y sus variantes advocacionales. Con el conocimiento de esta joya pretendemos el de esta sociedad que la disfrutó.

The author discusses the iconography of a type of cross, the jeweled cross, in the vast and complex context of traditional clothing in the area of Sierra de Francia and Candelario (Salamanca province, Spain). Upon the basis of fieldwork, archival documents -which date from the late 1500's through the 1870's-, and the observation of the witnessing piece, he analyze from an ethnohistorical perspective the material and formal aspects of this cross as well as its associations with various characters of the Catholic pantheon. A comprehensive knowledge of the jewel illuminates a great deal of the society that treasured it.

15 Cabe la posibilidad, ante la ambigüedad del documento, de que sean láminas o pinturas de devoción de las denominadas "de Valencia", como las "de Valladolid. Ver A. CEA GUTIÉRREZ, "Coleccionismo y devociones domésticas...”, RDTP, XIVIII (1993), pp. $245,271,280-281$.

16 Sobre la veneración doméstica y familiar a la cruz, y la ascendencia devocional del cristo de Burgos, ibid., pp. 231-233, 251-253 y 275. 